\title{
Two-dimensional Correlation Analysis of Raman Microspectroscopy of Subcellular Interactions of Drugs In Vitro
}

Hugh J. Byrne

Technological University Dublin, hugh.byrne@tudublin.ie

Franck Bonnier

Université Francois-Rabelais de Tours

Zeineb Farhane

Technological University Dublin, zeineb.farhane@tudublin.ie

Follow this and additional works at: https://arrow.tudublin.ie/nanolart

Part of the Pharmacology, Toxicology and Environmental Health Commons

\section{Recommended Citation}

Byrne, H.J., Bonnier, F. \& Farhane, Z. (2019). Two-dimensional correlation of raman microspectroscopy of subcellular interactions of drugs in vitro. Journal of Biophotonics, 12(3). doi:10.1002/jbio.20180032

This Article is brought to you for free and open access by the NanoLab at ARROW@TU Dublin. It has been accepted for inclusion in Articles by an authorized administrator of ARROW@TU Dublin. For more information, please contact arrow.admin@tudublin.ie, aisling.coyne@tudublin.ie,gerard.connolly@tudublin.ie.

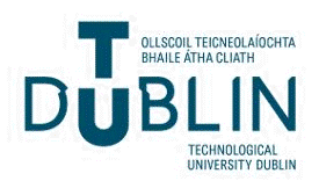




\title{
Two Dimensional Correlation Analysis of Raman microspectroscopy of subcellular interactions of drugs in vitro.
}

\author{
Hugh J. Byrne ${ }^{1 *}$, Franck Bonnier ${ }^{2}$, Zeineb Farhane $e^{1,3}$ \\ *Corresponding Author: E-mail: Hugh.Byrne@ dit.ie \\ ${ }^{1}$ FOCAS Research Institute, Dublin Institute of Technology, Kevin Street, Dublin 8, Ireland. \\ ${ }^{2}$ Université François-Rabelais de Tours, Faculty of Pharmacy, EA 6295 Nanomédicaments et \\ Nanosondes, 31 avenue Monge, 37200 Tours, France. \\ ${ }^{3}$ School of Physics and Clinical \& Optometric Sciences, Dublin Institute of Technology, \\ Kevin Street, Dublin 8, Ireland.
}

Keywords: Raman microspectroscopy, subcellular analysis, chemotherapeutic drugs, two dimensional correlation analysis

Short title: H.J. Byrne et al.: 2D-SCC of Raman analysis of drugs in cells

\begin{abstract}
:
Two dimensional correlation analysis is explored to data mine the time evolution of the characteristic Raman microspectroscopic signatures of the subcellular responses of the nucleoli of human lung cancer cells to the uptake of doxorubicin. A simulated dataset of experimental control spectra, perturbed with systematically time-dependent spectral changes, constituted by a short term response which represents the initial binding of the drug in the nucleolus, followed by a longer term response of the organelle metabolism, is used to validate the analysis protocol. Applying two dimensional correlation analysis, the in phase, synchronous correlation co-efficients are seen to contain contributions of both response profiles, whereas they can be independently extracted from the out of phase, asynchronous correlation co-efficients. The methodology is applied to experimental data of the uptake of doxorubicin in human lung cell lines to differentiate the signatures of chemical binding and subsequent cellular response.
\end{abstract}




\section{Introduction}

In the field of label free analysis and imaging, vibrational spectroscopic microscopy has emerged as an alternative for high content analysis of cells in vitro, which can provide molecularly specific signatures of biological processes and function. ${ }^{[1-3]}$ Quantitative spectroscopic changes attributable to the biochemical processes occurring during cell culture and mitosis, ${ }^{[4,5]}$ proliferation, ${ }^{[6]}$ differentiation and activation, ${ }^{[7-9]}$ adhesion, ${ }^{[10]}$ death $^{[11]}$ and invasion $^{[12]}$ have previously been documented. In particular, Raman microspectroscopy can be performed at visible wavelengths in a confocal mode and can provide details at a subcellular level, of fixed or live cells, ${ }^{[2,3,13]}$ enabling, for example, the detection of cellular mitochondrial distribution $^{[14]}$ and phagosomes. ${ }^{[15]}$

Both infrared absorption (IR) and Raman microspectroscopy have been used to assess the effects of drugs on cells, demonstrating the potential to measure changes in a label free, high throughput manner and therefore be used in pre-clinical drug screening. ${ }^{[16-19]}$ Raman microspectroscopic analyses of drug-cell interactions have focused both on changes in the cellular Raman spectra upon drug application, during intracellular tracking of the drug and its metabolites, as well as cellular resistance ${ }^{[20-22]}$

The emerging nonlinear Raman microspectroscopic techniques of coherent anti-Stokes and stimulated Raman scattering $^{[23]}$, and indeed technological advances in infrared spectroscopic analysis $^{[24,25]}$, promise label free high content spectroscopic analysis of sub-cellular processes in real-time, and hitherto unrivalled visualisation of cellular processes and function. It is becoming increasingly important, therefore, to explore protocols for harnessing and interpreting the high content spectral information which such label free techniques can yield. Critically, the analysis and interpretation of the spectral responses remains a challenge, even in the hands of "specialists". By their very nature, label free techniques register all species within the sampling area, and identification of specific responses requires multivariate 
analytical techniques to data-mine the differential signatures which are characteristic of cell injury events or response pathways.

Previous studies have demonstrated the ability of Partial Least Squares Regression (PLSR) and Independent Components Analysis (ICA), and/or a combination thereof, to monitor the uptake of chemotherapeutic agents, and to differentiate between the spectral signatures of the initial chemical binding of Cisplatin, ${ }^{[26,27]}$ Vincristine $^{[28]}$ and more recently Doxorubicin $(\mathrm{DOX})^{[29-32]}$ and Actinomycin $\mathrm{D}^{[33]}$ in A549 and Calu-1 human lung cancer cells from the subsequent cellular response pathway. Notably, however, in the case of the DOX study, the analysis was based on the identification of two independent regimes of the temporal spectral evolution, clearly identifiable by the build-up, and saturation of the DOX Raman signature, initially in the nucleolus ( 2-6 hrs), and subsequently nucleus of the cell ( $\sim 6-12 \mathrm{hrs})$, before it was detectable in the cytoplasmic region ( 24-48 hrs). The initial stages of the build up of the drug in the subcellular region were analysed independently from the regions of saturation, and the spectral signatures were interpreted in terms of the initial binding interactions of the drug in the organelle, and the subsequent metabolic response of the organelle. For automated analysis of more general cell exposure scenarios, in which for example the exogenous agent is not clearly identifiable in the cell by its strong Raman signature, an integrated objective multivariate data-mining algorithm is desirable.

Two dimensional correlation analysis is an alternative data analysis protocol, which was developed by Noda ${ }^{[34]}$ as a method of quantifying the relationship between spectral features that vary systematically as a function of an evolving parameter or physical quantity, such as time. Quaroni et al. ${ }^{[35]}$ have demonstrated its use to assign the biochemical origin of weak absorption changes in time-resolved FT-IR spectromicroscopy of individual cells, and to perform real-time metabolic analysis of living cancer cells. ${ }^{[36]}$ 
The application of two dimensional correlation analysis to a data set involves calculation of the correlation function of the evolving spectral profiles followed by application to the latter of a 2-D Fourier transform algorithm. The result is a complex function of two wavenumber variables that is plotted as separate real and imaginary components. The plot of the real component is called the synchronous plot, and that of the imaginary component the asynchronous plot. The former represents correlations between pairs of wavenumbers that evolve fully in phase, or with opposite phase. The latter represents correlations between pairs of wavenumbers that have an out-of-phase relationship. The principle of the technique is that the in phase spectral features should evolve synchronously with the time evolution, whereas the out of phase, asynchronous spectral features evolve over a later timescale. ${ }^{[37,38]}$ In this study, the potential of two dimensional correlation analysis to simultaneously identify, in a single analytical protocol, the characteristic of Raman microspectroscopic signatures of both the early stage binding of chemotherapeutic agents in the nucleolus of cells, as well as the subsequent cellular responses will be demonstrated. Raman microspectroscopic data from the previous studies of DOX uptake by and response of the nucleolar regions of A549 and Calu I (Supplemental Material), human lung cancer cells will be employed, and the results will be compared to those of the previous PLSR/ICA analysis. ${ }^{[39]}$ In order to validate the technique, simulated spectral datasets, based on systematic perturbations of the control datasets of the previous experimental studies, will be employed.

\section{Materials and Methods}

The details of experimental methods and protocols are described in greater detail in the original

publications ${ }^{[31,39-41]}$, but are summarised here. The experimental workflow of cell culture and drug exposure, for varying times, cytotoxicity assessment, fixation, subcellular Raman microscopic analysis, data preprocessing and analysis is depicted in Figure 1.

\subsection{Materials}


A549 human lung adenocarcinoma cells with the alveolar type II phenotype were obtained from ATTC (Manassas, VA, USA) and Calu-1 human lung epidermoid carcinoma cells were obtained from the European Collection of Cell Cultures.

Doxorubicin hydrochloride ${ }^{\circledR}$ powder (Sigma Life Sciences, Ireland) was diluted in $1 \mathrm{~mL}$ sterile water, to the required concentration of $0.6 \mu \mathrm{M}$, identified by cytotoxicological analysis ${ }^{[33,41]}$.

\subsection{Cell Culture}

A549 cells were cultured in DMEM (with $2 \mathrm{mM} \mathrm{L-glutamine)} \mathrm{with} 10 \%$ foetal bovine serum (FBS) and Calu- 1 cells in RPMI with $10 \%$ FBS, both at $37{ }^{\circ} \mathrm{C}$ in a humidified atmosphere containing $5 \%$ $\mathrm{CO}_{2}$ and cells were split every two days to maintain $\sim 60 \%$ confluence.

\subsection{Raman Spectroscopy}

Cells $\left(\sim 3 \times 10^{3} / \mathrm{cm}^{2}\right)$ were seeded and incubated on (20 mm diameter) $\mathrm{CaF}_{2}$ windows (Crystan Ltd, UK) for $24 \mathrm{hrs}$ for both control and exposure to chemotherapeutic drug. Medium was then removed and samples were rinsed twice with sterile phosphate buffered saline (PBS) and covered with aqueous solutions of DOX, of concentration $0.6 \mu \mathrm{M}$. After each incubation period, cells were washed twice with sterile PBS and fixed in formalin $(10 \%, 15 \mathrm{~min})$ and allowed to air dry.

A Horiba Jobin-Yvon LabRAM HR800 spectrometer with a $785 \mathrm{~nm}, 300 \mathrm{~mW}$ diode laser as source ( $100 \mathrm{~mW}$ at the sample), Peltier cooled 16-bit CCD, 300 lines/mm grating and $100 \mu \mathrm{m}$ confocal hole, was used for this work. Spectra were acquired from the three visually identifiable cell locations: cytoplasm, nucleus and nucleolus, in the range from $400 \mathrm{~cm}^{-1}$ to $1800 \mathrm{~cm}^{-1}$ with a x100 objective (LCPlanN, Olympus) for $30 \mathrm{~s}$ two times, to finally produce a data set of 30 points per cell location for each cell line, over a total of 210 different cells. In this study, only spectra of the nucleoli are considered.

\subsection{Data Processing and Analysis}

Raman spectral pre-processing and analysis were performed in Matlab using algorithms developed in house. Prior to analysis, background was subtracted using a NCLS (non-negatively constrained least 
squares) algorithm, spectra were smoothed (Savitsky-Golay filter 3th order, 11 points), baseline corrected (fifth order polynomial) and vector normalised.

Two dimensional correlation analysis was conducted using the MIDAS2010 Graphical User Interface (GUI) originally developed by researchers in the Canadian Light Source for two dimensional correlation analysis and data exploration of time resolved infrared spectra. ${ }^{[42]}$ The GUI is available for download from MathWorks File Exchange, ${ }^{[42]}$ and is recommended to be run in Matlab 7.6 (R2008a), with the Image Processing Toolbox. The spectral data should be loaded as a tab delimited text file with extension .txt, containing a matrix with [m n] dimensions. The first column of the matrix contains the spectral range (wavenumbers), while the remaining columns contain sample spectra. It is assumed that the dynamic variable (time), is incremented by a constant amount. Note, it was observed that the GUI does not read the final spectrum column, and therefore this was duplicated in a column $n+1$.

\section{Two dimensional correlation analysis of simulated spectral responses}

\subsection{Generation of Simulated Spectral Responses}

The analysis of the kinetic uptake of DOX by A549 cells and subsequent cellular response by Farhane et al. ${ }^{[39]}$ indicated the evolution of an initial response associated with the chemical interaction of the chemotherapeutic agent with the RNA/DNA in the nucleolus of the cell, and a subsequent longer term response associated with reaction of the cell metabolism. According to the observations of this study, a simplified representation of the initial response signature (Response 1) can be modelled based on a reduction of the prominent peaks observed at $785 \mathrm{~cm}^{-1}$ (RNA/DNA O-P-O stretching), $810 \mathrm{~cm}^{-1}$ (RNA O-P-O stretching), $1095 \mathrm{~cm}^{-1}$ (DNA PO${ }_{2}^{-}$symmetric stretching) and $1683 \mathrm{~cm}^{-1}$ (protein Amide I), as shown in Figure 2(a). Similarly, the spectral signature of the longer term cellular response (Response

2) can be represented by increases in the prominent peaks at $1047 \mathrm{~cm}^{-1}$ (RNA P-O stretching, 
sugar phosphate $-\mathrm{C}-\mathrm{O}-$-stretching), $1271 \mathrm{~cm}^{-1}$ (protein Amide III) and $1444 \mathrm{~cm}^{-1}$ (lipid $\mathrm{CH}_{2}$ deformation).

The time evolution of these responses can be modelled by a simple rate equation approach, such that:

The number of bound DOX molecules, $\mathrm{N}_{\mathrm{b}}$, is represented as a function of time by

$\mathrm{dN} / \mathrm{dt}=\left(\mathrm{N}_{\text {recp }}-\mathrm{N}_{\mathrm{b}}\right) \mathrm{K}_{\mathrm{up}} \mathrm{D}$

where $\mathrm{N}_{\text {recp }}$ is the number of receptor sites for DOX binding in the cell nucleolus, $\mathrm{D}$ is the DOX dose, and $\mathrm{K}_{\mathrm{up}}$ is the rate of uptake of DOX into the nucleolus of the cell. The spectral response of the cell to DOX binding is assumed to be instantaneous, and therefore the spectral response is weighted according to:

Response $1(\mathrm{t})=$ Response $1 \times \mathrm{N}_{\mathrm{b}}(\mathrm{t})$

The time evolution of the subsequent cellular response, $\mathrm{Nr}$, can similarly be modelled according to:

$\mathrm{dN}_{\mathrm{r}} / \mathrm{dt}=\left(\mathrm{N}_{\text {resp }}-\mathrm{N}_{\mathrm{r}}\right) \mathrm{K}_{\mathrm{resp}} \mathrm{N}_{\mathrm{b}}$

where $\mathrm{N}_{\text {resp }}$ acts as a limit to the total response, and $\mathrm{K}_{\text {resp }}$ is the response rate. The spectral response of the cell to DOX binding is assumed to evolve at this rate, and therefore the spectral response is weighted according to:

Response $2(\mathrm{t})=$ Response $2 \times \mathrm{N}_{\mathrm{r}}(\mathrm{t})$

Figure 2(b) shows the simulated temporal evolution of the spectral responses, using rates of $\mathrm{K}_{\text {up }}=2.5 \times 10^{-4}$ and $\mathrm{K}_{\mathrm{resp}}=5 \times 10^{-6} \mathrm{hr}^{-1}$.

To simulate the time evolution of the intrinsic spectral response of the nucleus of A549 cells to DOX exposure, the simulated spectral responses in Figure 2(a), can be added to the 
experimental mean control spectra (Figure 2(a)), weighted at a given exposure time by the simulated response of Figure 2(b). Response 1 is weighted negatively, to represent the experimentally observed reduction in the identified features of nucleic acids. In both cases, an additional weighting of 0.05 was applied, to better mimic the experimental observations.

Figure 2(c) shows a zoom of the spectral region from $700-1200 \mathrm{~cm}^{-1}$, illustrating the control spectrum and the simulated spectra at (as examples) 20 and $72 \mathrm{hrs}$ DOX exposure.

\subsection{D Correlation Analysis of Simulated Spectral Responses}

The simulated spectral response data set, including simulated responses over the exposure period of 0-72 hrs, at 2 hour intervals, was analysed using the MIDAS 2010 two dimensional correlation analysis GUI package. ${ }^{[42]}$ Figure 3a shows the synchronous correlation analysis in contour form, while Figure $\mathbf{3 b}$ shows the same plot, after subtraction of the control spectrum (0 hrs) from the dataset, as a static component. Both are symmetric with respect to the diagonal, as expected. Before subtraction, the 2D contour plot shows multiple positive correlations for all peaks, and the diagonal cross section contains contributions of all spectral components integrated over the exposure time range (data not shown). Subtraction of the static component greatly simplifies the correlation plot, as shown in Figure 3b. Again, the diagonal autocorrelation shows positive peaks for all spectral features of Response 1 and Response 2, as shown in Figure 4(a). Features of the off diagonal, cross peaks represent positive correlations for Response 1, and negative correlations for Response 2. A vertical cross section at $\mathrm{x}=785 \mathrm{~cm}^{-1}$, shown in Figure 4(b), demonstrates that the spectral contributions of both Response 1 and Response 2 are represented, although with opposite signs to their contributions to the source spectra. The same applies to a horizontal crosssection at $y=785 \mathrm{~cm}^{-1}$. Furthermore, although their contributions are weighted equally in the simulated spectra, the relative contributions of the spectral responses to the correlation is not the same, Response 2 being relatively weaker. Notably, with no a priori knowledge of the 
origin of the features, it is not obvious that negative and positive correlations have different temporal evolutions. Although Response 1 and 2 have clearly different temporal profiles, they both evolve synchronously as a function of time.

Figure 5(a) shows the asynchronous correlation plot, which in this case is independent of subtraction of control and, as expected, is asymmetric with respect to the diagonal. Reading vertically at a (x) wavenumber corresponding to a feature of Response 1 , the features of Response 2 are positively, asynchronously correlated, while reading vertically at wavenumbers of Response 2 features, Response 1 features are negatively, asynchronously correlated, as shown in Figure 5(b). The behaviour is inverted when reading horizontally from (y) wavenumbers of Response 1 or Response 2 features. Furthermore, although not identical, the weightings of the two Response features are approximately equal.

The asynchronous contour plot thus clearly better illustrates that the spectral profile of Response 1 and Response 2 are decoupled and can be differentiated by two dimensional correlation analysis. The synchronous autocorrelation can be employed to identify the spectral features of the changes to the system, while the features of the asynchronous correlation plot can be employed to differentiate the responses of differing time evolution.

Notably, however, the analysis does little to elucidate the temporal evolution of the responses, as simulated according to Figure 2. In fact, although the diagonal autocorrelation of Figure 3 reproduces the spectral perturbations of Figure 2, the weightings of Response 1 and 2 are not equal, as shown in Figure 4(a), as the correlation function integrates over the exposure time of 72 hours. Figure 6(a) shows a plot of the correlation over an expanding time window of 0-T, as $\mathrm{T}$ is increased from $4 \mathrm{hrs}$ to $72 \mathrm{hrs}$ (i.e. $0-2 \mathrm{hrs}, 0-4 \mathrm{hrs}, 0-6 \mathrm{hrs}$ etc.). The integrated contribution of the Response 1 feature at $785 \mathrm{~cm}^{-1}$, for example, is considerably stronger than that of Response 2 at $1047 \mathrm{~cm}^{-1}$ over the time range. If the correlation is instead performed 
over a fixed, moving window, $\Delta \mathrm{T}$ (e.g. 0-4hrs, 2-6hrs, 4-8hrs etc.), the temporal evolution of the respective spectral features is better reproduced, as shown in Figure $\mathbf{6}(\mathbf{b})$ for $\Delta \mathrm{T}=4 \mathrm{hrs}$. This is done by manually limiting the dataset to the range T1-T2, and extracting the correlation data for each range, which is rather laborious and is not easily facilitated by the MIDAS 2010 GUI. Rather, the MIDAS 2010 GUI plots features of the original spectral data as a function of time, whether before or after subtraction of a static background, if appropriately identified by the correlation procedure (Figure 6(c)).

\section{Two dimensional correlation analysis of Experimental Datasets}

\subsection{A549 Nucleolus after DOX exposure}

Figure 7(a) shows the synchronous contour plot of the two dimensional correlation analysis of experimental data of Raman microspectroscopic analysis of the nucleoli of A549 cells exposed to DOX at the $\mathrm{IC}_{50}$ concentration of $0.6 \mu \mathrm{M}(24 \mathrm{hrs}$, MTT assay) over a period of 072 hrs, as reported by Farhane et al.. ${ }^{[39]}$ The zero hour control has been subtracted as a static component. Figure 7(b) shows the corresponding asynchronous contour plot. The diagonal autocorrelation profile is dominated by the spectrum of DOX, as shown in Figure 8, which has strong features at, for example, $440 \mathrm{~cm}^{-1}, 465 \mathrm{~cm}^{-1}$ (C-C-O and C-O), bands corresponding to $\mathrm{C}-\mathrm{O}, \mathrm{C}-\mathrm{O}-\mathrm{H}$ and $\mathrm{C}-\mathrm{H}$ in the region between 1200 and $1300 \mathrm{~cm}^{-1}$, and at 1445 and $1570 \mathrm{~cm}^{-1}$, related to skeletal ring vibrations ${ }^{[43,44]}$. In addition, there are a number of weaker peaks evident in the region of $\sim 780 \mathrm{~cm}^{-1}, 1000-1100 \mathrm{~cm}^{-1}$, and $\sim 1600 \mathrm{~cm}^{-1}$, which represent the cellular responses to DOX exposure ${ }^{[39]}$.

By analogy to the analysis of the simulated spectral model of Section 3, the independent evolutions of the spectral responses are best extracted by analysis of the asynchronous correlation plot (Figure 7(b)). Of specific interest is the instantaneous response of cellular spectral features as a result of DOX binding, which are directly correlated with the time dependent evolution of the DOX spectrum, as represented by the strongest DOX peak at 1217 
$\mathrm{cm}^{-1}$ and the subsequent evolution of the cellular spectra as a result of the interaction. Figure 9(a) shows the vertical cross section of the asynchronous correlation analysis at a wavenumber of $1217 \mathrm{~cm}^{-1}$. The appearance of characteristic DOX features at $\sim 440 \mathrm{~cm}^{-1}$ and $1220 \mathrm{~cm}^{-1}$ may be the result of metabolisation or aggregation of the drug in the cell nucleolus. Additional prominent features at $\sim 1047 \mathrm{~cm}^{-1}, 1200-1300 \mathrm{~cm}^{-1}$, and $\sim 1440 \mathrm{~cm}^{-1}$ may be associated with the long term cellular response to drug binding in the nucleolus of the cell. The spectral profile of the vertical cross section at $1047 \mathrm{~cm}^{-1}$ reveals negatively correlated features at $785 \mathrm{~cm}^{-1}$ and 810 $\mathrm{cm}^{-1}$, as well as a weaker feature at $\sim 1090 \mathrm{~cm}^{-1}$ and a broader feature at $\sim 1640 \mathrm{~cm}^{-1}$, as shown in Figure 9(b).

By analogy to the analysis of the simulated data of Figure 3, the peaks of the asynchronous features identified in figures 9 can be considered to be associated with spectroscopic signatures of the responses of the nucleolus to uptake of the chemotherapeutic agent, DOX (b), and the subsequent cellular responses (a), respectively. The initial response is correlated with the DOX spectroscopic profile and thus may be considered as the signature of the initial chemical binding of the DOX with nucleolar RNA, while the second spectral signature, asynchronous with the DOX signature, is characteristic of the subsequent cellular response, in the nucleolus. Figure 10 plots the temporal evolution of the spectral features, after subtraction of the control spectrum, of the DOX exposed A549 nucleolus, at $465 \mathrm{~cm}^{-1}$ (DOX), $785 \mathrm{~cm}^{-1}$ (RNA/DNA O$\mathrm{P}-\mathrm{O}$ stretching) and $1047 \mathrm{~cm}^{-1}$ (RNA P-O stretching, sugar phosphate $-\mathrm{C}-\mathrm{O}-$ stretching). The (negative) evolution of the $785 \mathrm{~cm}^{-1}$ feature clearly follows that of the characteristic $465 \mathrm{~cm}^{-1}$ DOX feature, saturating at $\sim 12 \mathrm{hrs}$. The feature at $1047 \mathrm{~cm}^{-1}$ continues to evolve, however, as the metabolism of the nucelolus responds to the drug interactions.

The previous study by Farhane et al. ${ }^{[39]}$ using multivariate statistical analysis, consisting of Partial Least Squares Regression (PLSR) and Independent Components Analysis (ICA) showed a similar chemical binding signature in the nucleoli of the cells after short term DOX 
exposure for both A549 and Calu-1 cell lines, related to RNA/DNA interaction, resulting in a decrease of both bands at $785 \mathrm{~cm}^{-1}$ (DNA backbone $\mathrm{O}-\mathrm{P}-\mathrm{O}$ ) and $813 \mathrm{~cm}^{-1}$ (RNA O-P-O phosphodiester band stretching). The signatures of the nucleolar interactions for both cell lines are remarkably similar to the profile of the $\left(1047 \mathrm{~cm}^{-1}\right)$ cross section of the asynchronous component of the two dimensional correlation analysis, further associating it with the signature of the direct binding of the drug in the cell.

The uptake of DOX in the nucleolus, and the DOX-RNA/DNA intercalation is seen to saturate after 2-6 hrs. ${ }^{[39]}$ After saturation, for the nucleolar regions, Independent Components Analysis (ICA) of the later exposure times revealed a notable decrease in cellular features at $728 \mathrm{~cm}^{-1}$ (adenine) $785 \mathrm{~cm}^{-1}$ (cytosine, thymine and DNA backbone $\mathrm{O}-\mathrm{P}-\mathrm{O}$ ), $813 \mathrm{~cm}^{-1}$ (RNA O-P-O stretching), $1095 \mathrm{~cm}^{-1}$ (DNA $\mathrm{PO}_{2^{-}}$symmetric stretching) and $1376 \mathrm{~cm}^{-1}$ (thymine), consistent with a decrease in nucleic acid contributions due to the DOX mechanism of action inducing alteration of nucleolar structure, size, shape and as a consequence cellular apoptosis. ${ }^{[41]}$ These characteristics are consistent with the features of the $\left(1217 \mathrm{~cm}^{-1}\right)$ cross section of the asynchronous component of the two dimensional correlation analysis.

Notably, very similar profiles were observed for the case of Raman microspectroscopic analysis of the nucleolar regions of similarly DOX exposed Calu 1, non-small-cell lung cancer cells, as shown in Supplemental Figures S1-S2. It is notable, however, that the asynchronous cross sections of A549 and Calu 1 cells (Figure S2(b)) at $1217 \mathrm{~cm}^{-1}$ are significantly different. This was also observed in the multivariate analysis of Farhane et al. ${ }^{[39]}$ and was proposed to potentially hold the key to the different sensitivities of the two cell lines to the drug, related to anti-apoptotic and DNA repair mechanisms. ${ }^{[31]}$

\section{Conclusions}


As example of a label free analytical technique, Raman microspectroscopy has been demonstrated to be a viable alternative to expensive and time consuming conventional high content analysis protocols. Nevertheless, it is important that the information that the spectral profiling can yield can be effectively and efficiently data mined. This work demonstrates that two dimensional correlation analysis of Raman microspectroscopic signatures of the subcellular interactions of drugs in vitro can identify and differentiate the characteristic signatures of the initial chemical binding of the drug, and the subsequent cellular response, in a single operation. The use of simulated datasets provides a valuable validation of the technique, confirming that the true temporal evolutions of the identified characteristic features are faithfully reproduced. The study further illustrates the potential of Raman microspectroscopic subcellular analysis for cytological processes, and the similarities of the initial binding signatures in different cell lines suggest applications for in vitro preclinical candidate drug screening, which the differences in the response signatures for different cell lines suggest sensitivities of the technique to cellular resistance pathways and potential applications in patient screening for Companion Diagnostics strategies.

\section{Supporting Information}

Additional supporting information may be found in the online version of this article at the publisher's website.

Figure S1: (a) Synchronous contour plot of the two dimensional correlation analysis of experimental data of Raman microspectroscopic analysis of the nucleoli of Calu 1 cells exposed to DOX. The 0 hrs non exposed control has been subtracted as a static component. (b) Asynchronous contour plot of the two dimensional correlation analysis of experimental data of Raman microspectroscopic analysis of the nucleoli of Calu 1 cells exposed to DOX. The dashed lines indicates the vertical cross sections at $1047 \mathrm{~cm}^{-1}$ and $1217 \mathrm{~cm}^{-1}$. 
Figure S2: (a) Vertical cross section of the asynchronous correlation analysis (Figure S1(b)) at a wavenumber of $1217 \mathrm{~cm}^{-1}$. (b) Vertical cross section of the asynchronous correlation analysis (Figure S1(b)) at a wavenumber of $1047 \mathrm{~cm}^{-1}$.

Acknowledgements This work was supported by Science Foundation Ireland, SFI 11/PI/08.

\section{References}

[1] Z. Farhane, H. Nawaz, F. Bonnier, H. J. Byrne, J. Biophotonics 2018, 11, e201700258.

[2] E. Efeoglu, M. A. Maher, A. Casey, H. J. Byrne, Anal. Bioanal. Chem. 2018, 410, $1631-1646$.

[3] H. J. Byrne, F. Bonnier, A. Casey, M. Maher, J. McIntyre, E. Efeoglu, Z. Farhane, Appl. Opt., AO 2018, 57, E11-E19.

[4] S. Boydston-White, M. Romeo, T. Chernenko, A. Regina, M. Miljković, M. Diem, Biochim. Biophys. Acta 2006, 1758, 908-14.

[5] C. Matthäus, S. Boydston-White, M. Miljković, M. Romeo, M. Diem, Appl. Spectrosc. 2006, 60, 1-8.

[6] K. W. Short, S. Carpenter, J. P. Freyer, J. R. Mourant, Biophys. J. 2005, 88, 4274-88.

[7] D. Ami, T. Neri, A. Natalello, P. Mereghetti, S. M. Doglia, M. Zanoni, M. Zuccotti, S. Garagna, C. A. Redi, Biochim. Biophys. Acta - Mol. Cell Res. 2008, 1783, 98-106.

[8] I. Notingher, I. Bisson, A. E. Bishop, W. L. Randle, J. M. P. Polak, L. L. Hench, Anal. Chem. 2004, 76, 3185-3193.

[9] N. Pavillon, A. J. Hobro, S. Akira, N. I. Smith, Proc. Natl. Acad. Sci. U. S. A. 2018, 
115, E2676-E2685.

[10] A. D. Meade, F. M. Lyng, P. Knief, H. J. Byrne, Anal. Bioanal. Chem. 2007, 387, $1717-1728$.

[11] F. Gasparri, M. Muzio, Biochem. J. 2003, 369, 239-48.

[12] K.-Z. Liu, L. Jia, S. M. Kelsey, A. C. Newland, H. H. Mantsch, APOPTOSIS 2001, 6, 269-278.

[13] A. J. Hobro, N. I. Smith, Vib. Spectrosc. 2017, 91, 31-45.

[14] C. Matthäus, T. Chernenko, J. A. Newmark, C. M. Warner, M. Diem, Biophys. J. 2007, 93, 668-73.

[15] H.-J. van Manen, Y. M. Kraan, D. Roos, C. Otto, Proc. Natl. Acad. Sci. U. S. A. 2005, 102, 10159-10164.

[16] C. Hughes, G. Clemens, M. J. Baker, Trends Biotechnol. 2015, 33, 429-30.

[17] A. Derenne, V. Van Hemelryck, D. Lamoral-Theys, R. Kiss, E. Goormaghtigh, Biochim. Biophys. Acta - Mol. Basis Dis. 2013, 1832, 46-56.

[18] A. Derenne, R. Gasper, E. Goormaghtigh, Analyst 2011, 136, 1134-1141.

[19] L. E. Jamieson, H. J. Byrne, Vib. Spectrosc. 2017, 91, 16-30.

[20] K. le Roux, L. C. Prinsloo, D. Meyer, Appl. Phys. Lett. 2014, 105, 123702.

[21] H. K. Yosef, L. Mavarani, A. Maghnouj, S. Hahn, S. F. El-Mashtoly, K. Gerwert, Anal. Bioanal. Chem. 2015, 407, 8321-31.

[22] S. F. El-Mashtoly, D. Petersen, H. K. Yosef, A. Mosig, A. Reinacher-Schick, C. Kötting, K. Gerwert, Analyst 2014, 139, 1155. 
[23] C. H. Camp Jr, Y. J. Lee, J. M. Heddleston, C. M. Hartshorn, A. R. H. Walker, J. N. Rich, J. D. Lathia, M. T. Cicerone, Nat. Photonics 2014, 8, 627-634.

[24] M. J. Pilling, A. Henderson, P. Gardner, Anal. Chem. 2017, 89, DOI 10.1021/acs.analchem.7b00426.

[25] B. Bird, J. Rowlette, Analyst 2017, 142, DOI 10.1039/c6an02080a.

[26] H. Nawaz, F. Bonnier, P. Knief, O. Howe, F. M. Lyng, A. D. Meade, H. J. Byrne, in Analyst, 2010, pp. 3070-3076.

[27] H. Nawaz, F. Bonnier, A. D. Meade, F. M. Lyng, H. J. Byrne, Analyst 2011, 136, $2450-2463$.

[28] H. Nawaz, A. Garcia, A. D. Meade, F. M. Lyng, H. J. Byrne, Analyst 2013, 138, 6177.

[29] Z. Farhane, F. Bonnier, A. Casey, H. J. Byrne, Analyst 2015, 140, 4212-4223.

[30] E. Szafraniec, K. Majzner, Z. Farhane, H. J. Byrne, M. Lukawska, I. Oszczapowicz, S. Chlopicki, M. Baranska, Spectrochim. Acta Part A Mol. Biomol. Spectrosc. 2016, 169, $152-160$.

[31] Z. Farhane, F. Bonnier, M. A. Maher, J. Bryant, A. Casey, H. J. Byrne, J. Biophotonics 2017, 10, 151-165.

[32] Z. Farhane, F. Bonnier, H. J. Byrne, Anal. Bioanal. Chem. 2017, 409, 1333-1346.

[33] Z. Farhane, F. Bonnier, H. J. Byrne, J. Biophotonics 2018, 11, e201700112.

[34] I. Noda, J. Am. Chem. Soc. 1989, 111, 8116-8118.

[35] L. Quaroni, T. Zlateva, E. Normand, Anal. Chem. 2011, 83, 7371-7380.

[36] L. Quaroni, T. Zlateva, Anal. Chem. 2014, 86, 6887-6895. 
[37] I. Noda, Biomed. Spectrosc. Imaging 2015, 4, 109-127.

[38] T. Pazderka, V. Kopeck, "2D Correlation Spectroscopy and its Application in Matlab," can be found under http://dsp.vscht.cz/konference_matlab/MATLAB08/prispevky/081_pazderka.pdf, n.d.

[39] Z. Farhane, F. Bonnier, H. J. Byrne, Anal. Bioanal. Chem. 2017, 409, 1333-1346.

[40] Z. Farhane, F. Bonnier, O. Howe, A. Casey, H. J. Byrne, J. Biophotonics 2017, 11, e201700060.

[41] Z. Farhane, F. Bonnier, A. Casey, H. J. Byrne, Analyst 2015, 140, 4212-4223.

[42] “MIDAS 2010 - File Exchange - MATLAB Central,” can be found under https://uk.mathworks.com/matlabcentral/fileexchange/32384-midas-2010, n.d.

[43] C. Eliasson, A. Lorén, K. V Murty, M. Josefson, M. Käll, J. Abrahamsson, K. Abrahamsson, Spectrochim. Acta. A. Mol. Biomol. Spectrosc. 2001, 57, 1907-15.

[44] N. Strekal, A. German, G. Gachko, A. Maskevich, S. Maskevich, J. Mol. Struct. 2001, $563-564,183-191$. 
Figure 1: Schematic representation of workflow of (i) cell culture (ii) drug exposure (iii) cytotoxicity assessment (iv) cell fixation and subcellular Raman microspectroscopic analysis (v) data preprocessing (v) two dimensional correlation analysis

(i)

(ii)

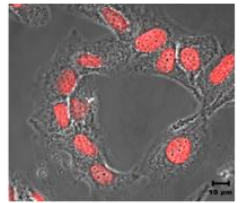

(iii)

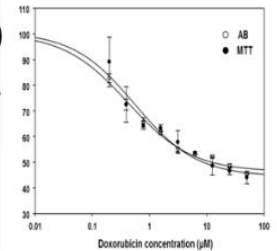

(iv)

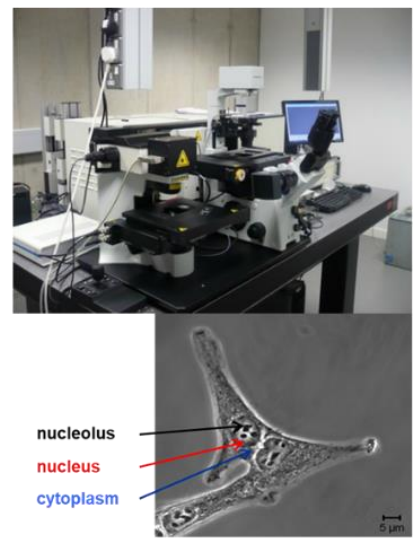

(v)

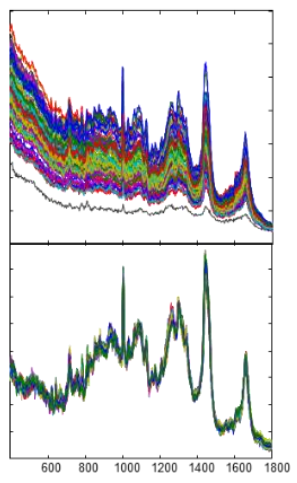

(vi)

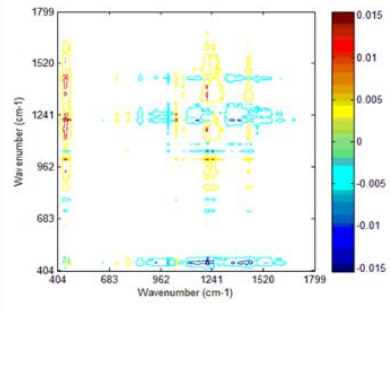


Figure 2: (a) Average Control spectra of the nucleoli of A549 cells. Also shown are the simulated spectral signatures of DOX binding (Response 1) and subsequent cellular response (Response 2). Spectra are normalised to a maximum intensity of 1. Band wavenumbers are: 1. $785 \mathrm{~cm}^{-1}, 2.810 \mathrm{~cm}^{-1}, 3.1047 \mathrm{~cm}^{-1}, 4.1095 \mathrm{~cm}^{-1}, 5.1271 \mathrm{~cm}^{-1}, 6.1444 \mathrm{~cm}^{-1}, 7.1683 \mathrm{~cm}^{-1}$, (b) Simulated time evolution of the cellular spectral responses to DOX uptake in the A549 cell nucleolus, (c) Mean Control spectra of A549 nucleolus, and spectra with added simulated responses, between 700 and $1200 \mathrm{~cm}^{-1}$, after 20 and $72 \mathrm{hrs}$ DOX exposure.

(a)

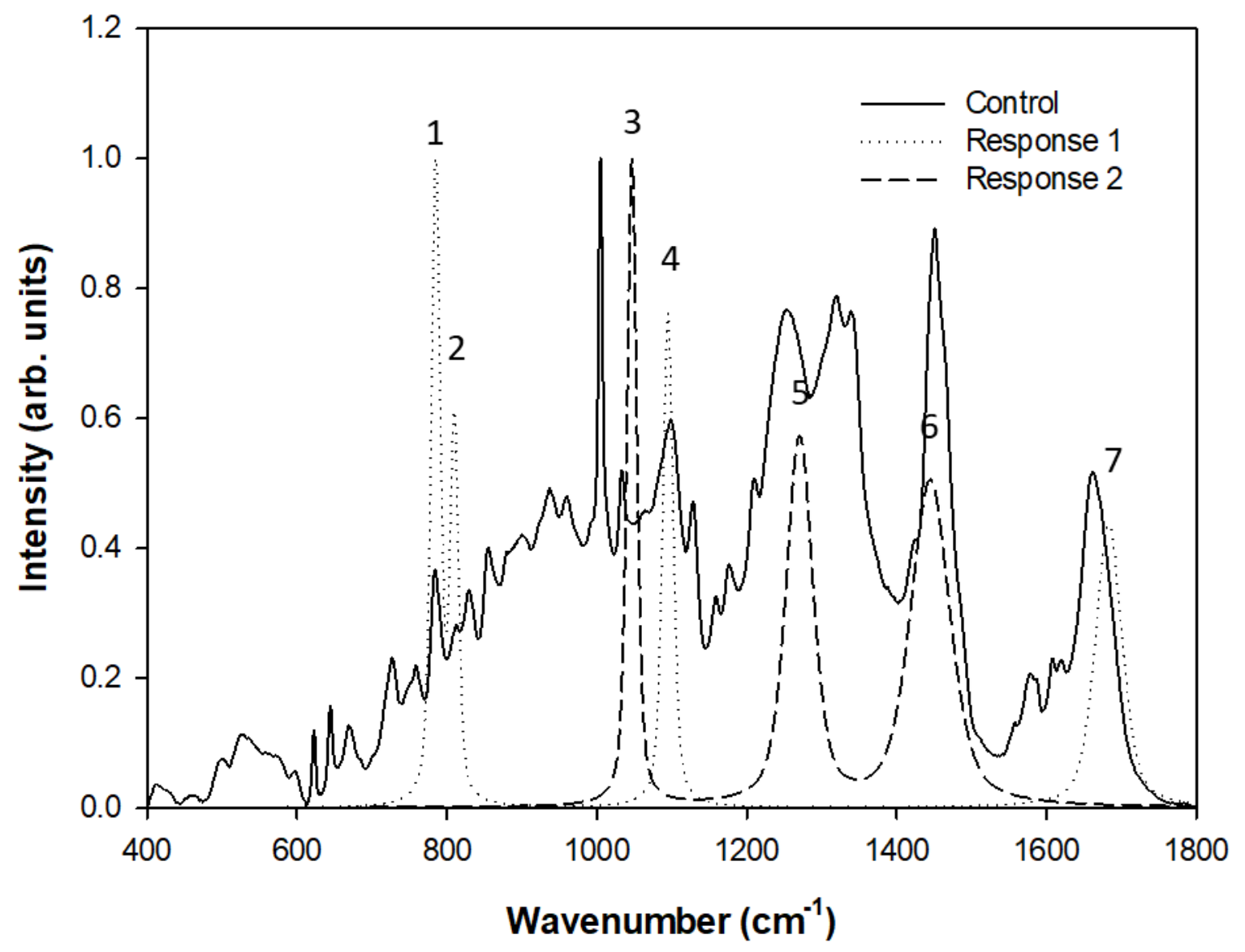


(b)

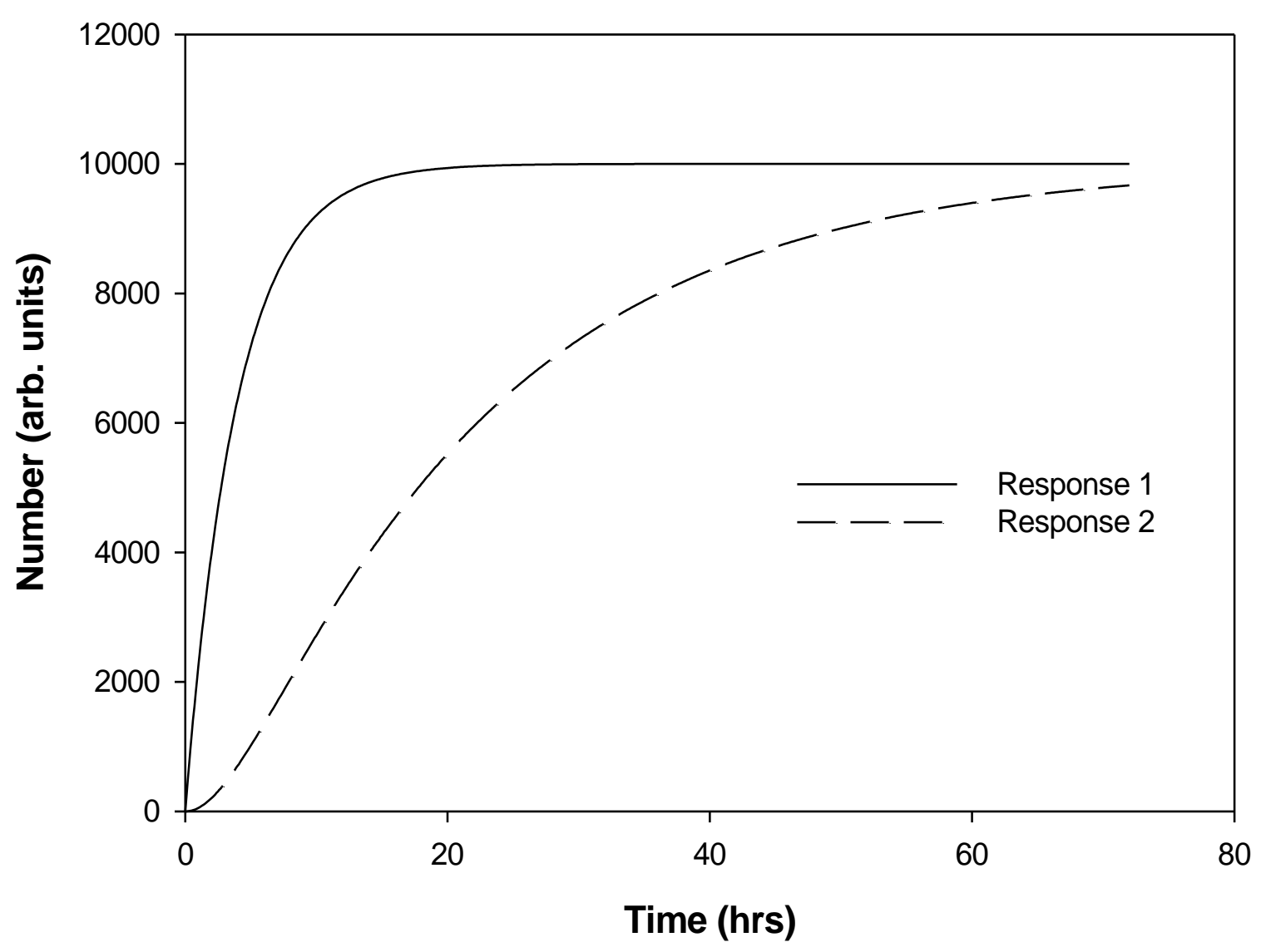


(c)

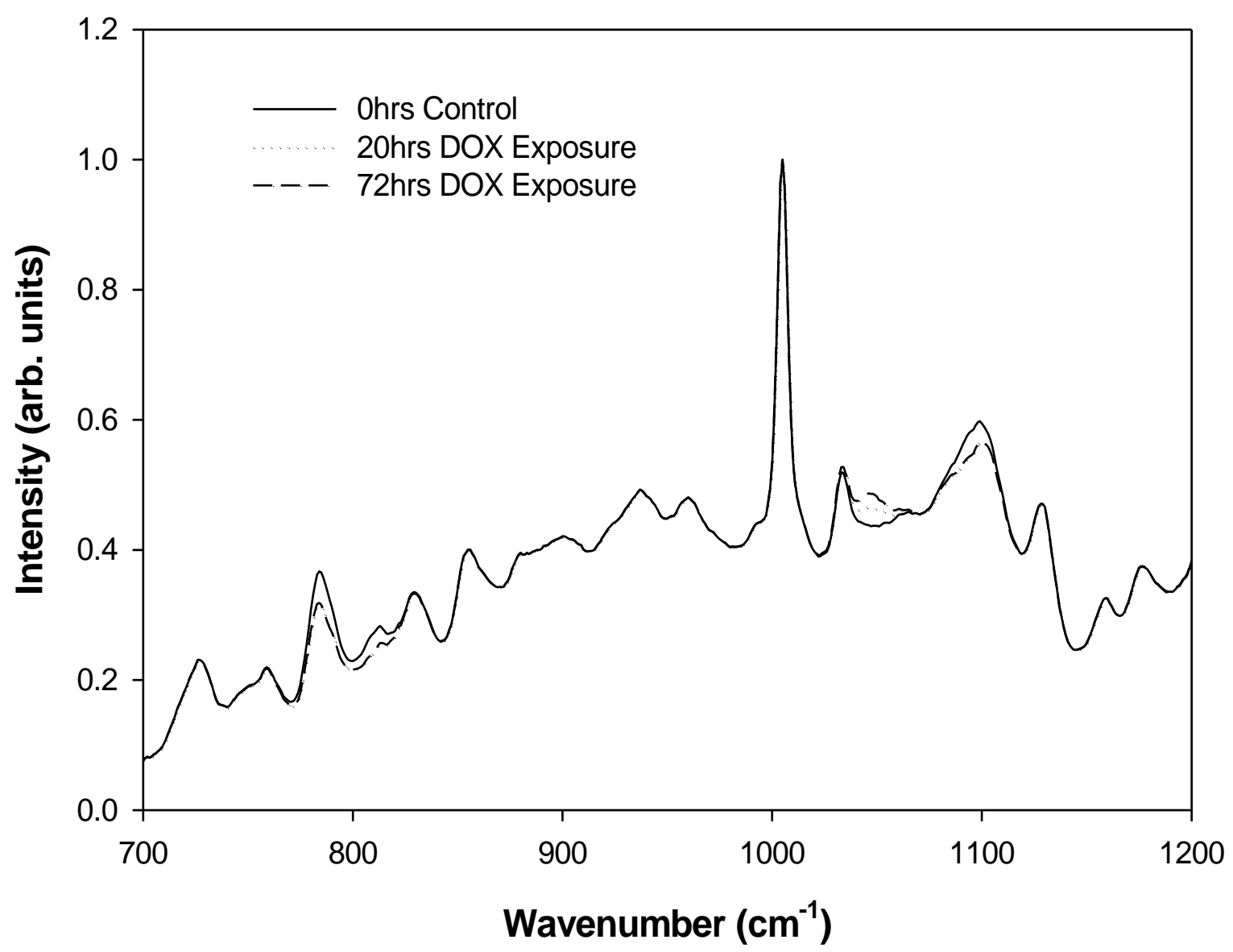


Figure 3: Synchronous contour plot of two dimensional correlation analysis of A549 nucleolar spectra with simulated response to DOX exposure over the time period 0-72 hrs, (a) before and (b) after subtraction of the control (0 hrs) spectrum as static component. Dashed lines in (b) show the autocorrelation diagonal and the vertical cross section at $\mathrm{x}=785 \mathrm{~cm}^{-1}$.

(a)

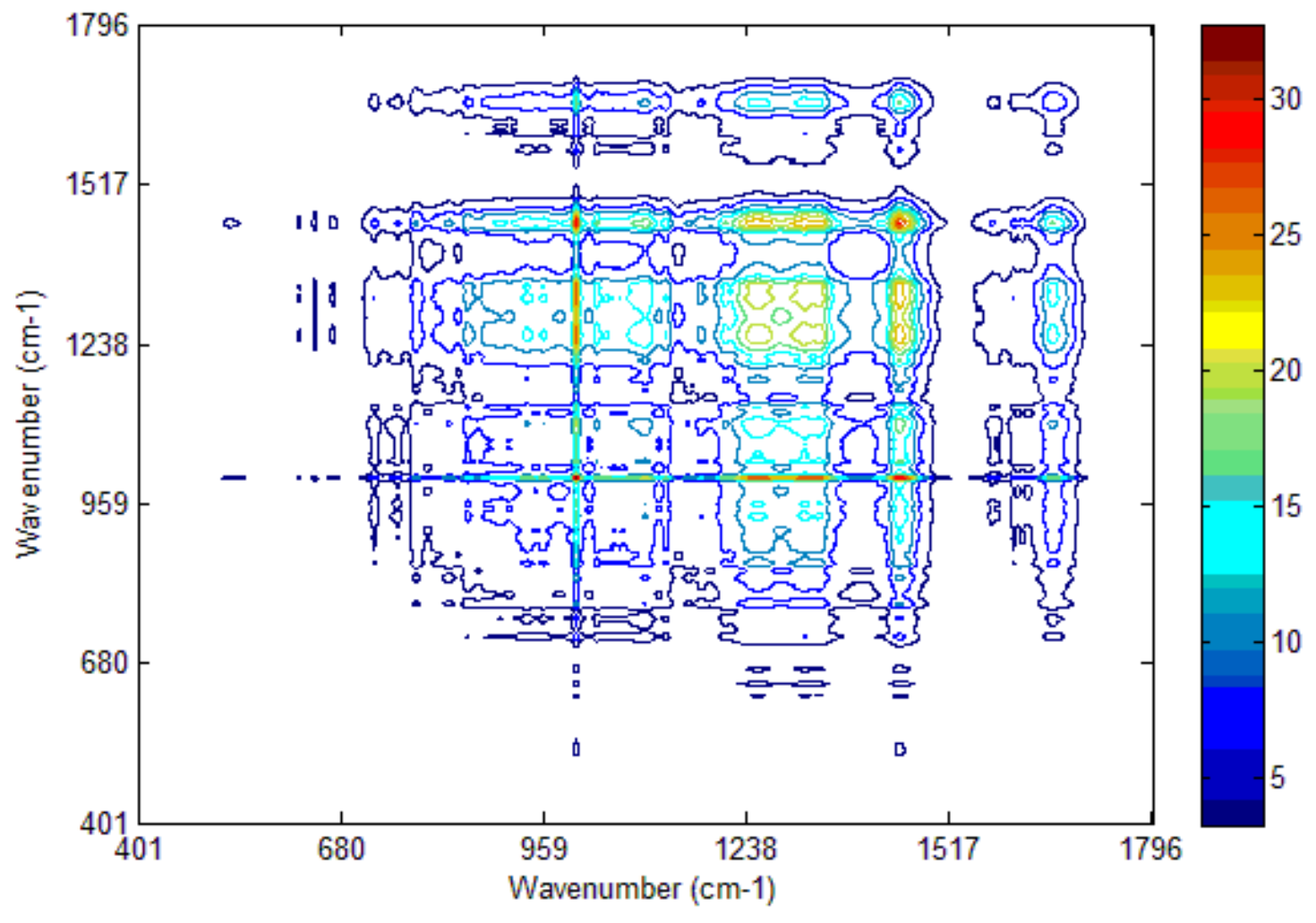


(b)

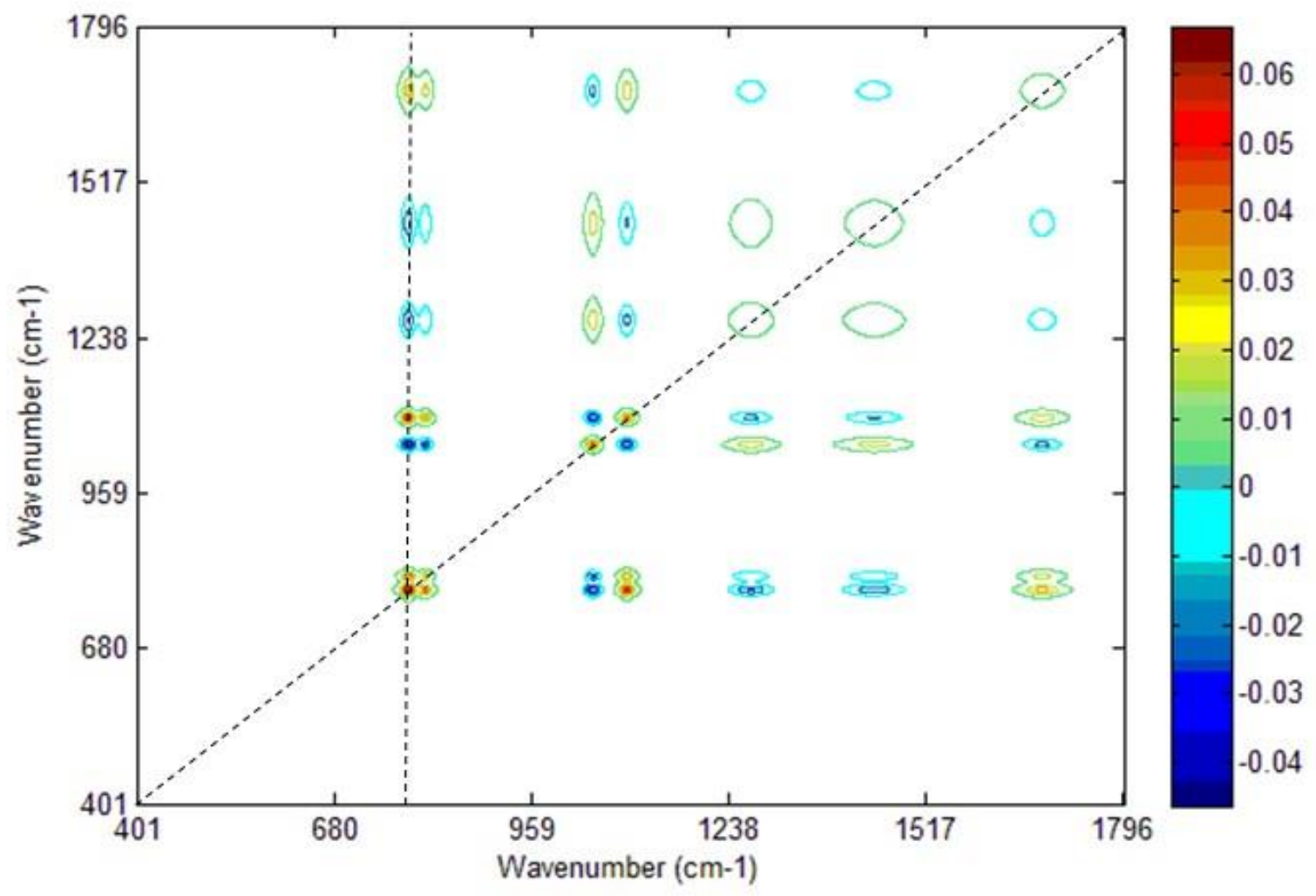


Figure 4 (a) Diagonal autocorrelation peaks of two dimensional correlation analysis of A549 nucleolar spectra with simulated response to DOX exposure over the time period 0-72 hrs. (b) vertical section of synchronous correlation analysis at $785 \mathrm{~cm}^{-1}$, after subtraction of the control (0hr) spectrum as static component. Band wavenumbers are: $1.785 \mathrm{~cm}^{-1}, 2.810 \mathrm{~cm}^{-1}, 3.1047$ $\mathrm{cm}^{-1}, 4.1095 \mathrm{~cm}^{-1}, 5.1271 \mathrm{~cm}^{-1}, 6.1444 \mathrm{~cm}^{-1}, 7.1683 \mathrm{~cm}^{-1}$

(a)

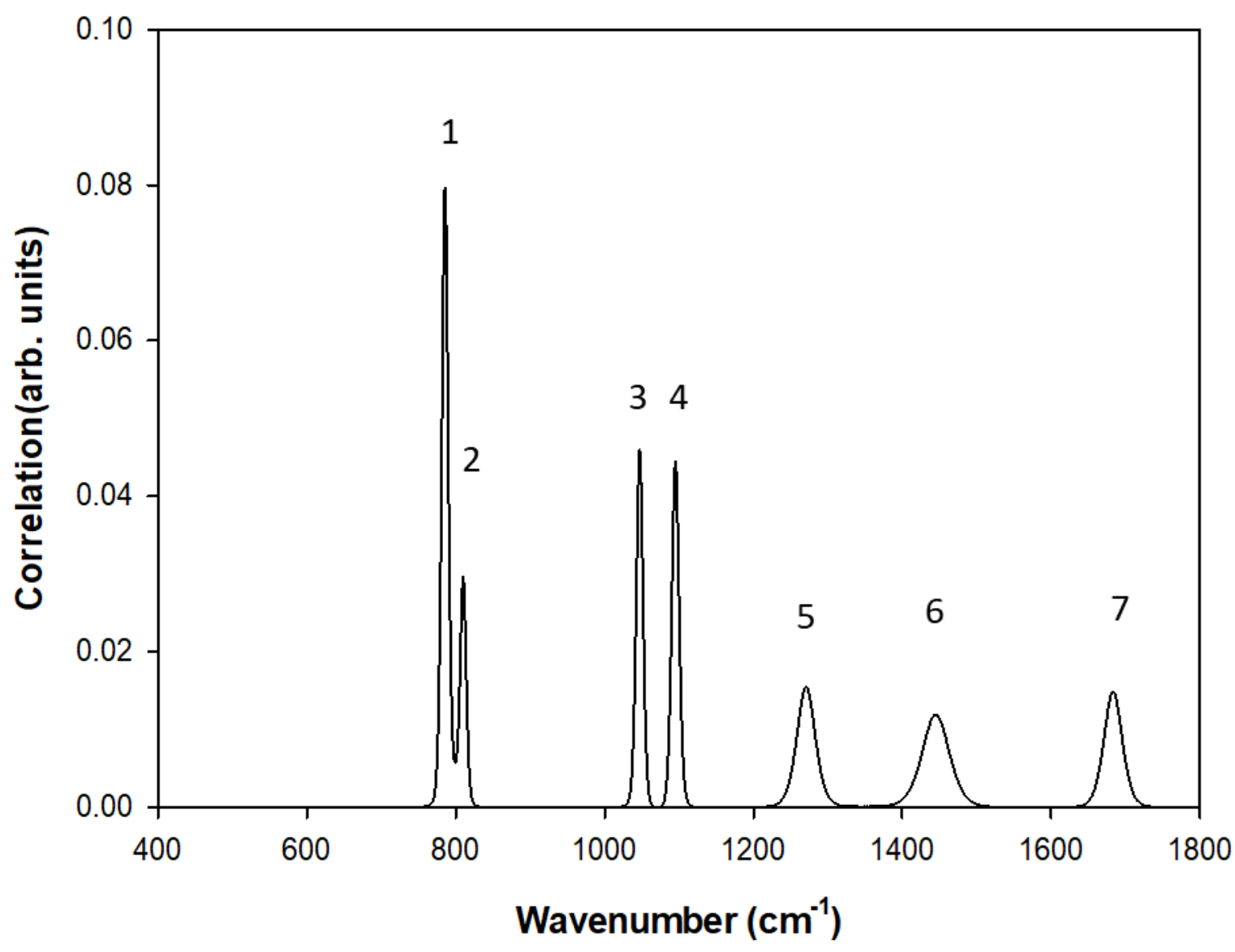


(b)

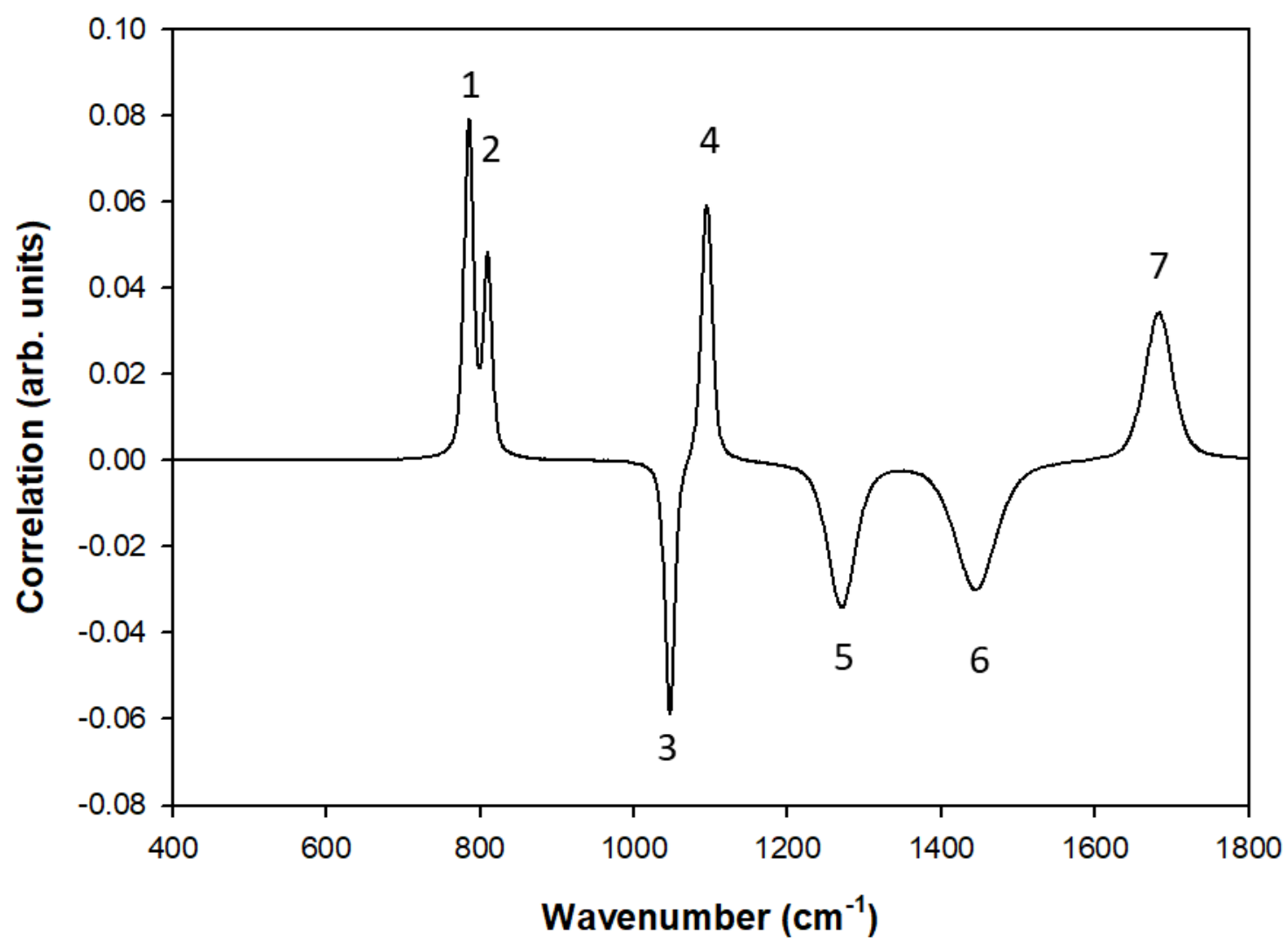


Figure 5: (a) Asynchronous contour plot of two dimensional correlation analysis of A549 nucleolar spectra with simulated response to DOX exposure over the time period 0-72 hrs. Dashed lines show the diagonal and vertical cross sections at $\mathrm{x}=785 \mathrm{~cm}^{-1}$ and $\mathrm{x}=1047 \mathrm{~cm}^{-1}(\mathrm{~b})$ vertical section of asynchronous correlation analysis at $785 \mathrm{~cm}^{-1}$ (solid line) and $1047 \mathrm{~cm}^{-1}$ (dotted line). Band wavenumbers are: $1.785 \mathrm{~cm}^{-1}, 2.810 \mathrm{~cm}^{-1}, 3.1047 \mathrm{~cm}^{-1}, 4.1095 \mathrm{~cm}^{-1}, 5$. $1271 \mathrm{~cm}^{-1}, 6.1444 \mathrm{~cm}^{-1}, 7.1683 \mathrm{~cm}^{-1}$

(a)

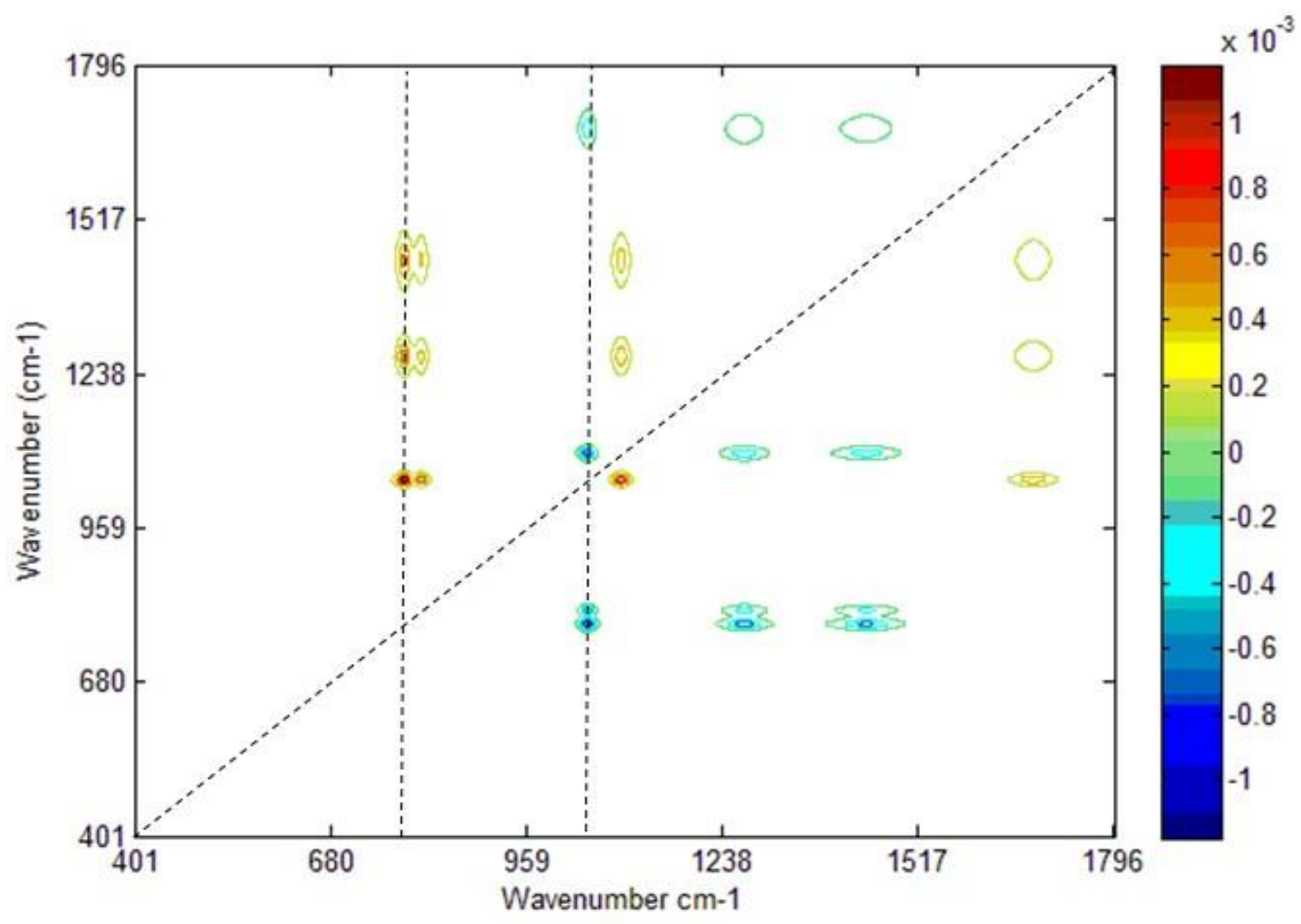


(b)

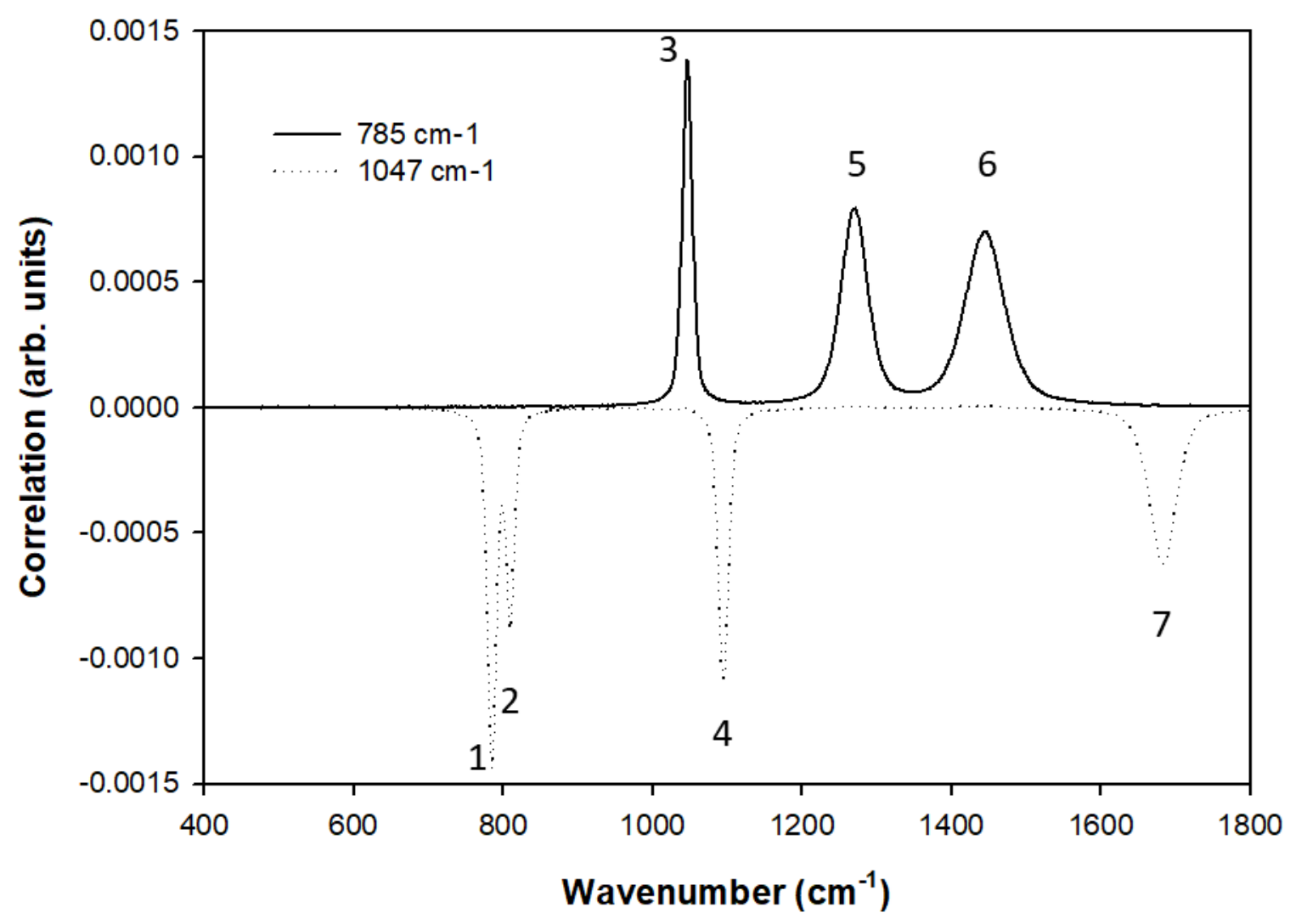


Figure 6: Autocorrelation intensity for the features at $785 \mathrm{~cm}^{-1}$ and $1047 \mathrm{~cm}^{-1}$, with (a) an increasing correlation window 0 - $\mathrm{T}$, in intervals of $4 \mathrm{hrs}(\mathrm{b})$ a moving correlation window $\Delta \mathrm{T}=$ 4hrs. (c) shows the evolution of the spectral features at $785 \mathrm{~cm}^{-1}$ (Response 1) and $1047 \mathrm{~cm}^{-1}$ (Response 2) as identified by the MIDAS 2010, after subtraction of the static component.

(a)

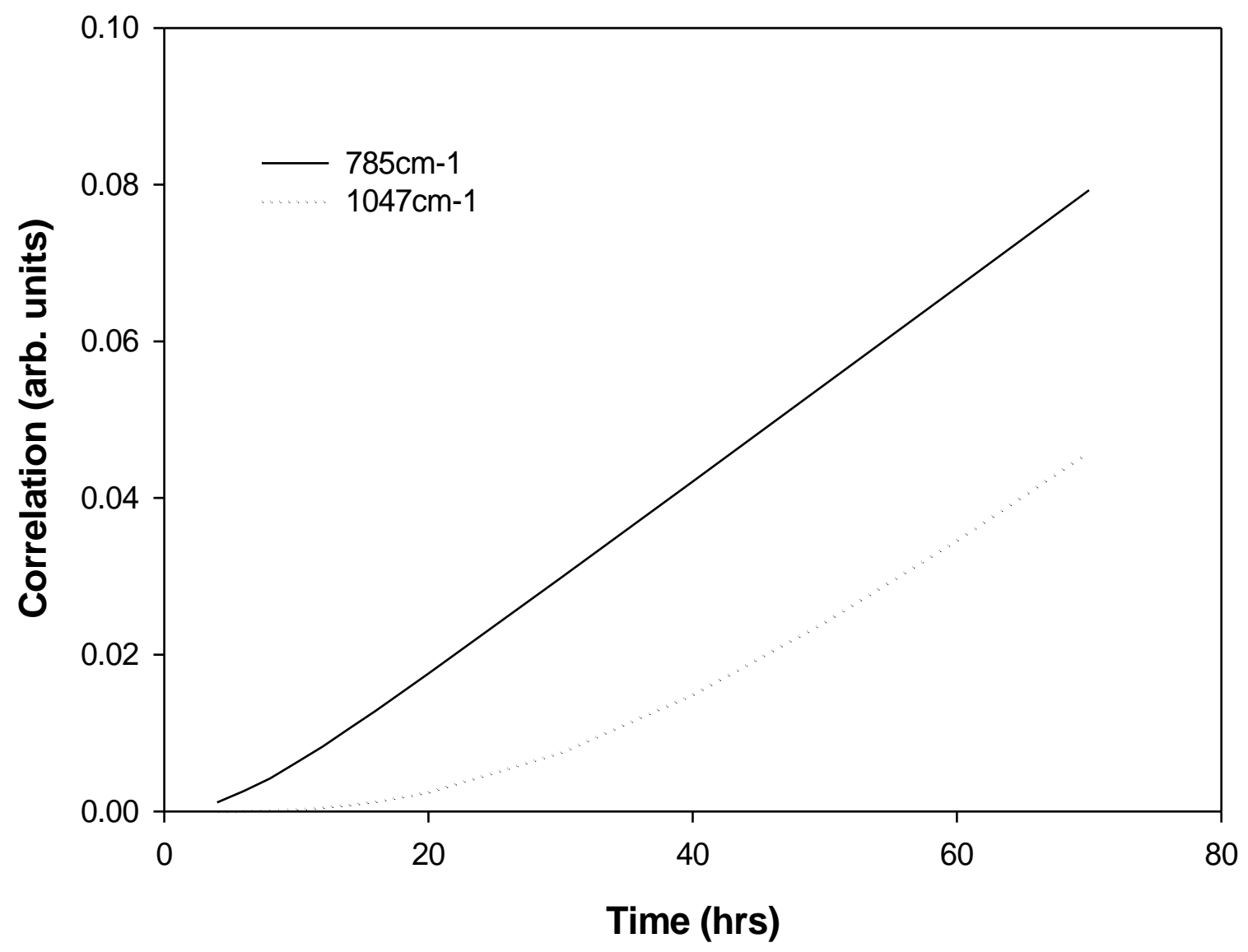


(b)

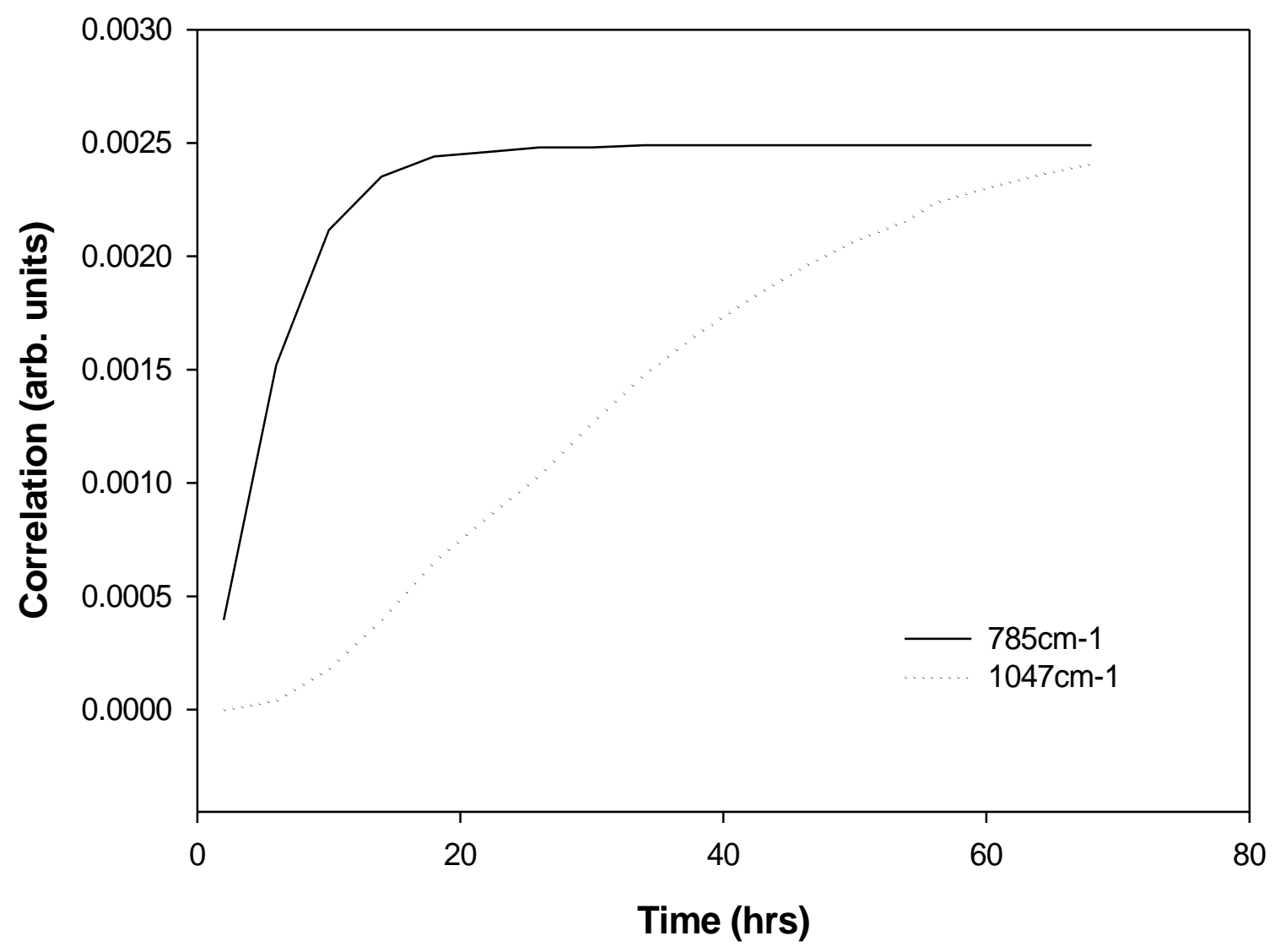


(c)

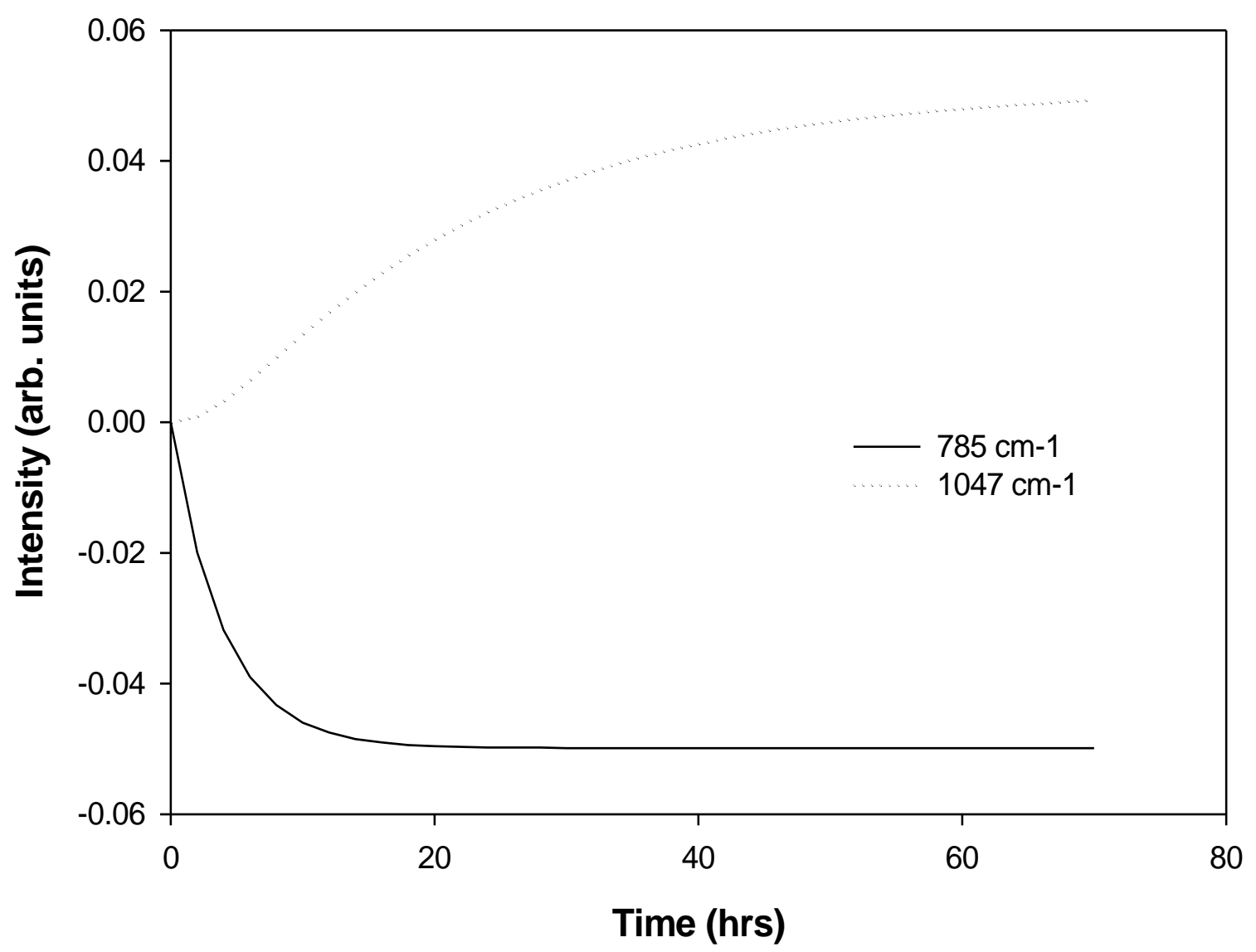


Figure 7: (a) Synchronous contour plot of the two dimensional correlation analysis of experimental data of Raman microspectroscopic analysis of the nucleoli of A549 cells exposed to DOX. The $0 \mathrm{hrs}$ non exposed control has been subtracted as a static component. (b) Asynchronous contour plot of the two dimensional correlation analysis of experimental data of Raman microspectroscopic analysis of the nucleoli of A549 cells exposed to DOX. The dashed lines indicate the vertical cross sections at $1047 \mathrm{~cm}^{-1}$ and $1217 \mathrm{~cm}^{-1}$.

(a)

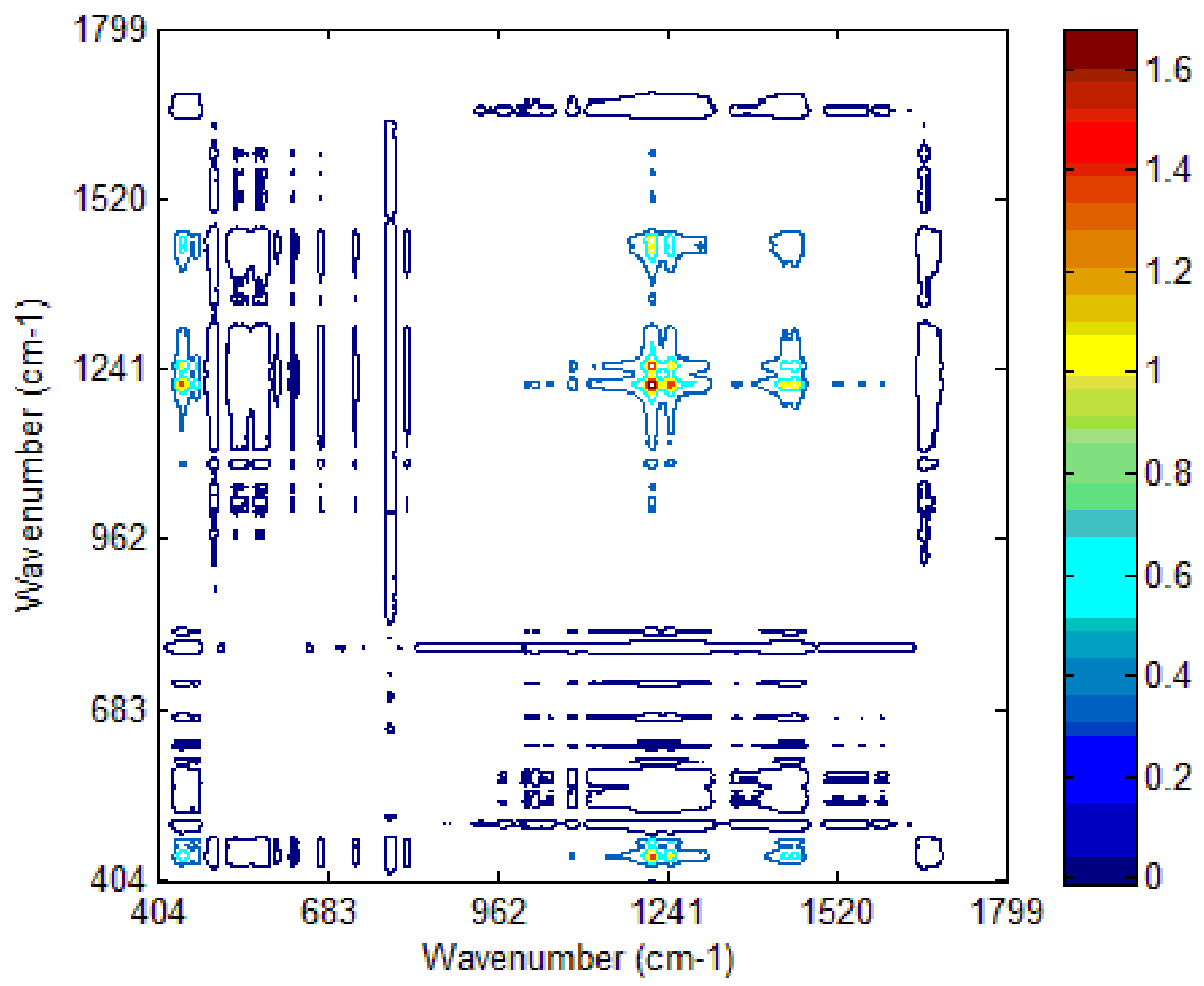


(b)

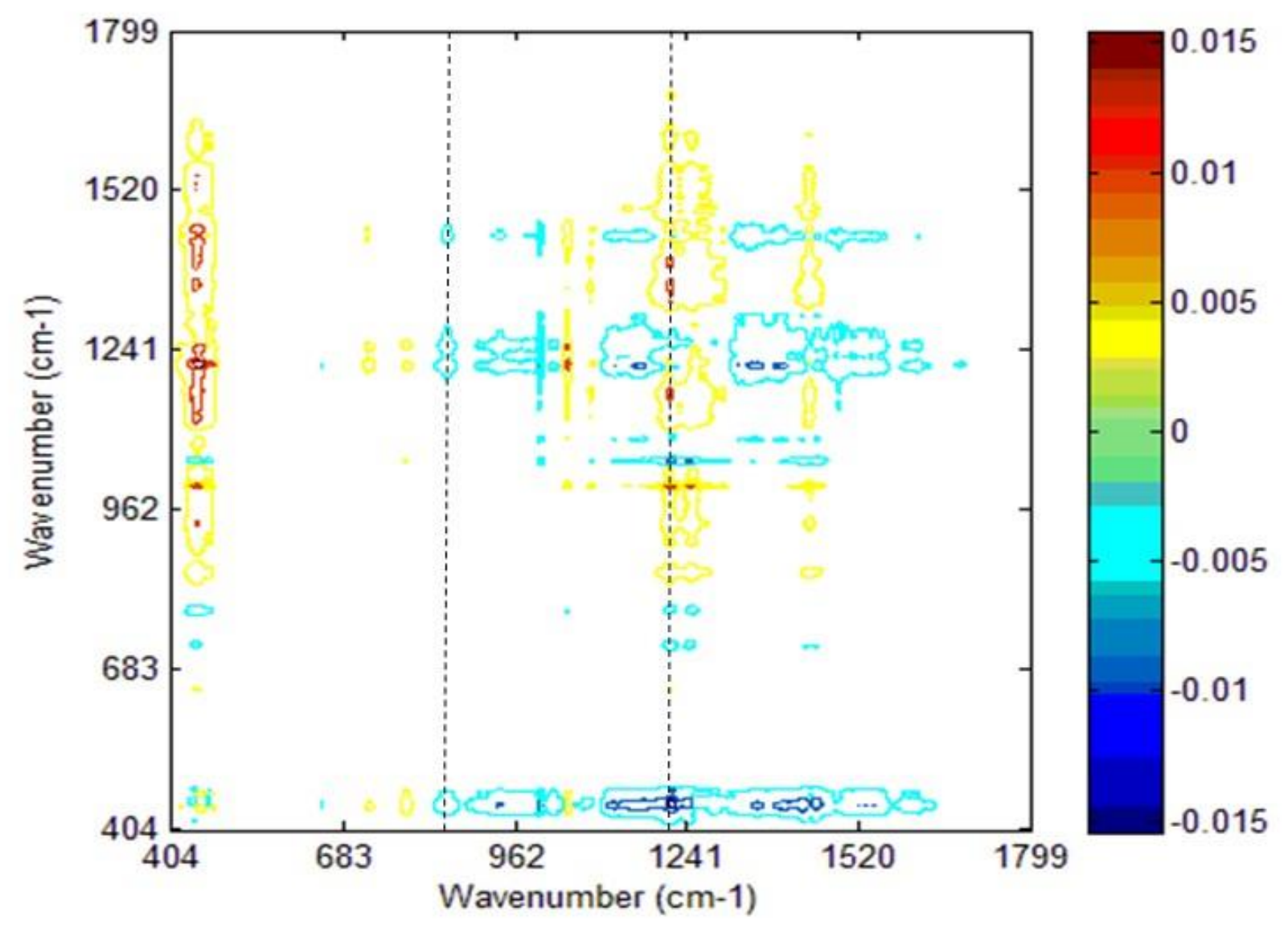


Figure 8: Diagonal autocorrelation of (Figure 7(a)) synchronous correlation analysis of experimental data of Raman microspectroscopic analysis of the nucleoli of A549 cells exposed to DOX. The 0 hrs non exposed control has been subtracted as a static component. Characteristic DOX features are indicated as: $1.440 \mathrm{~cm}^{-1}, 2.465 \mathrm{~cm}^{-1}, 3.1200 \mathrm{~cm}^{-1}, 4.1300$ $\mathrm{cm}^{-1}, 5.1445 \mathrm{~cm}^{-1}, 6.1570 \mathrm{~cm}^{-1}$.

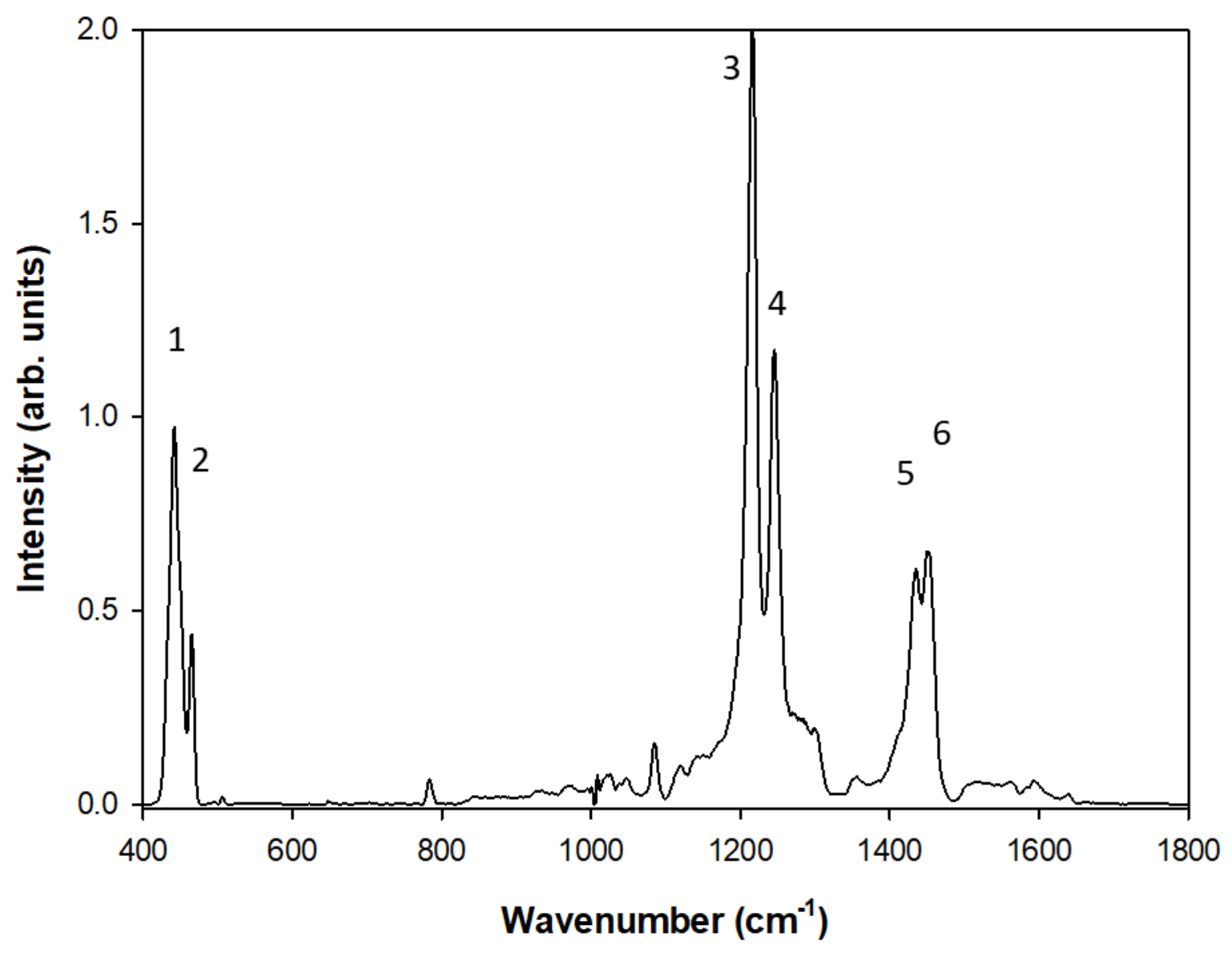


Figure 9: (a) Vertical cross section of the asynchronous correlation analysis (Figure 7(b)) at a wavenumber of $1217 \mathrm{~cm}^{-1}$. DOX features are indicated by $1.440 \mathrm{~cm}^{-1}, 4.1220 \mathrm{~cm}^{-1}$. Cellular response features are indicated by $2.1047 \mathrm{~cm}^{-1}, 3.1200 \mathrm{~cm}^{-1}, 5.1300 \mathrm{~cm}^{-1}, 6.1440 \mathrm{~cm}^{-1}$ (b) Vertical cross section of the asynchronous correlation analysis (Figure 7(b)) at a wavenumber of $1047 \mathrm{~cm}^{-1}$. Features at $1.785 \mathrm{~cm}^{-1}, 2.810 \mathrm{~cm}^{-1}, 3.1090 \mathrm{~cm}^{-1}, 4 . \sim 1640 \mathrm{~cm}^{-1}$ are indicated.

(a)

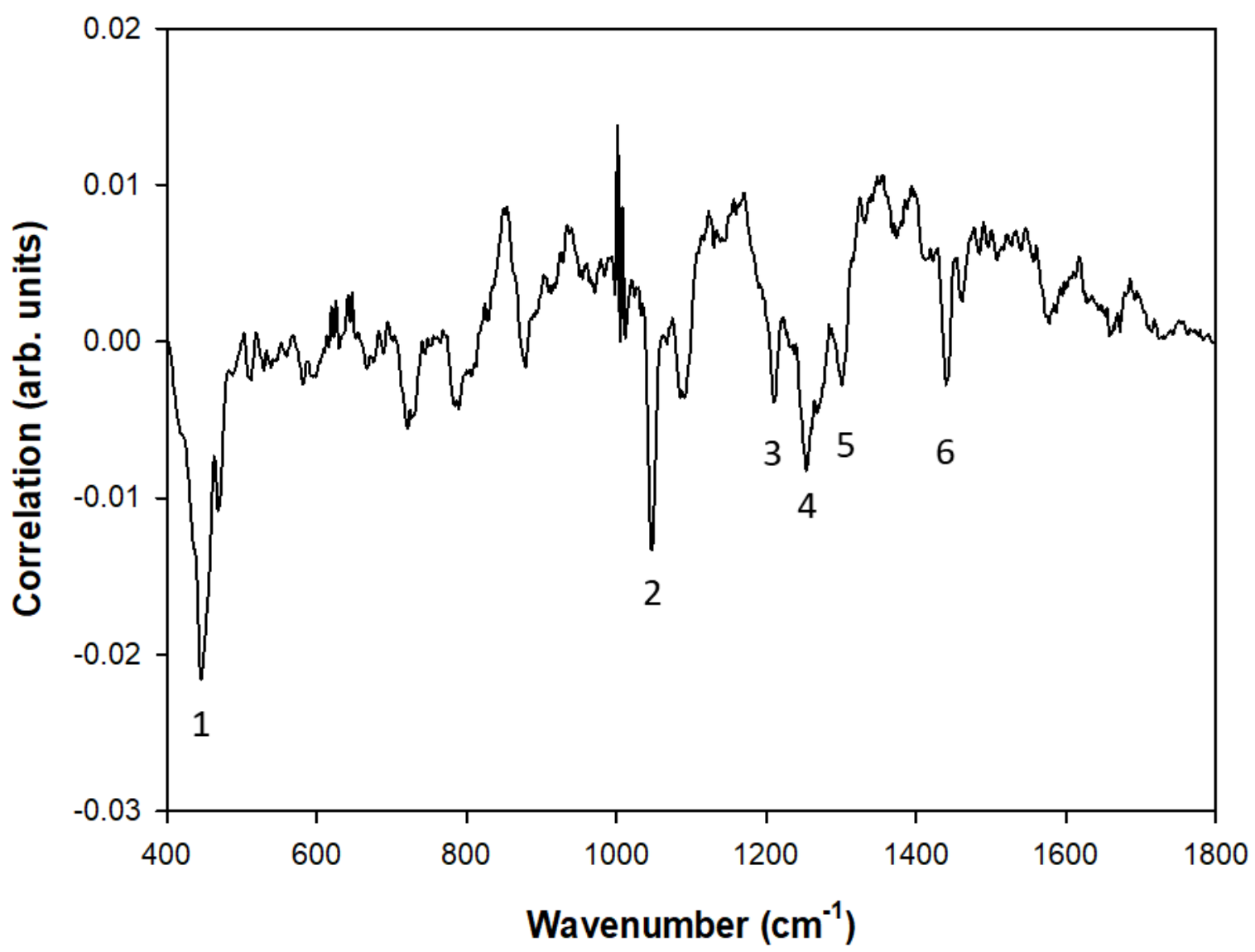


(b)

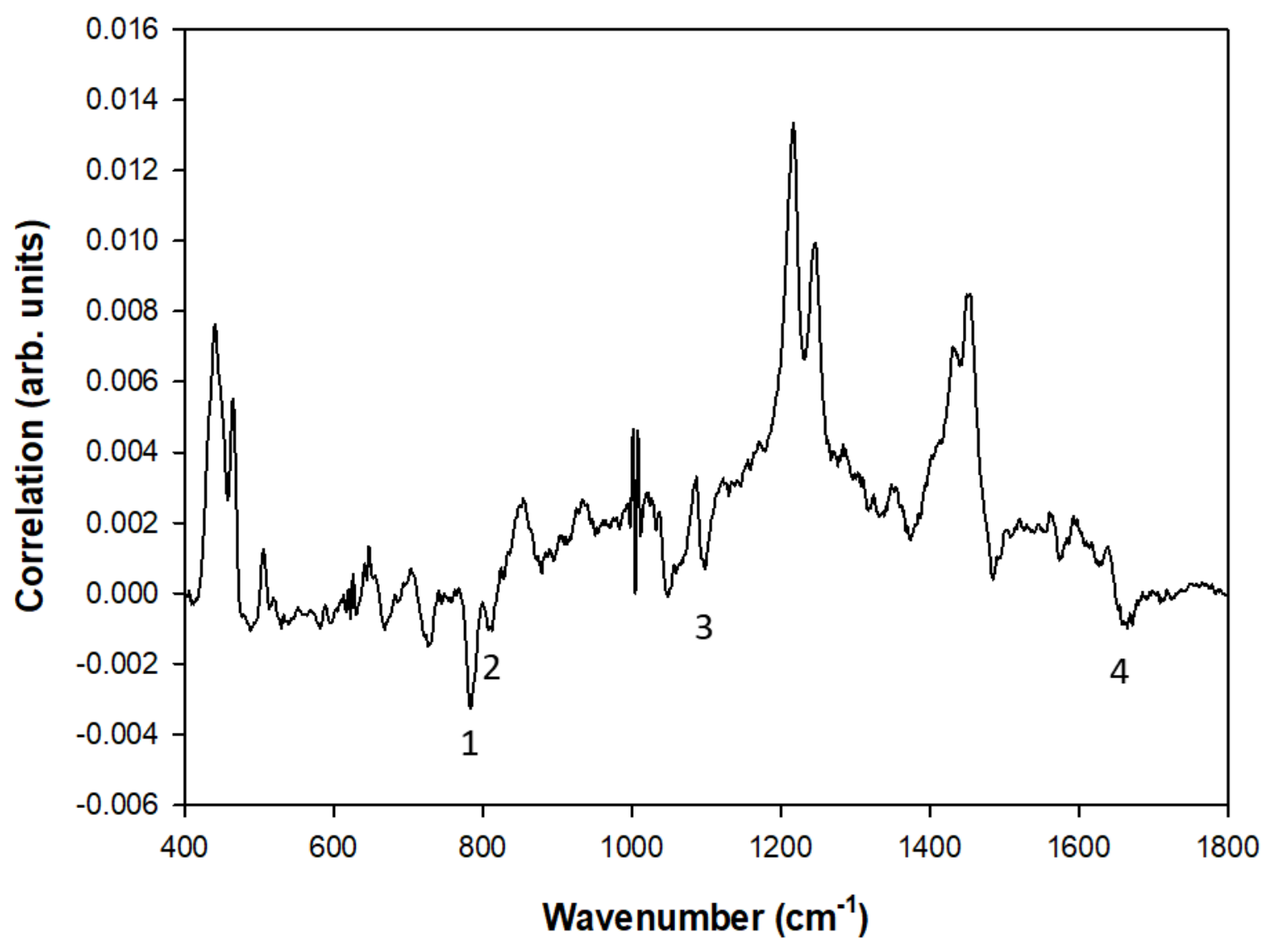


Figure 10: Temporal evolution of the spectroscopic features of the DOX exposed A549 nucleolus as a function of time. Solid lines are a guide to the eye.

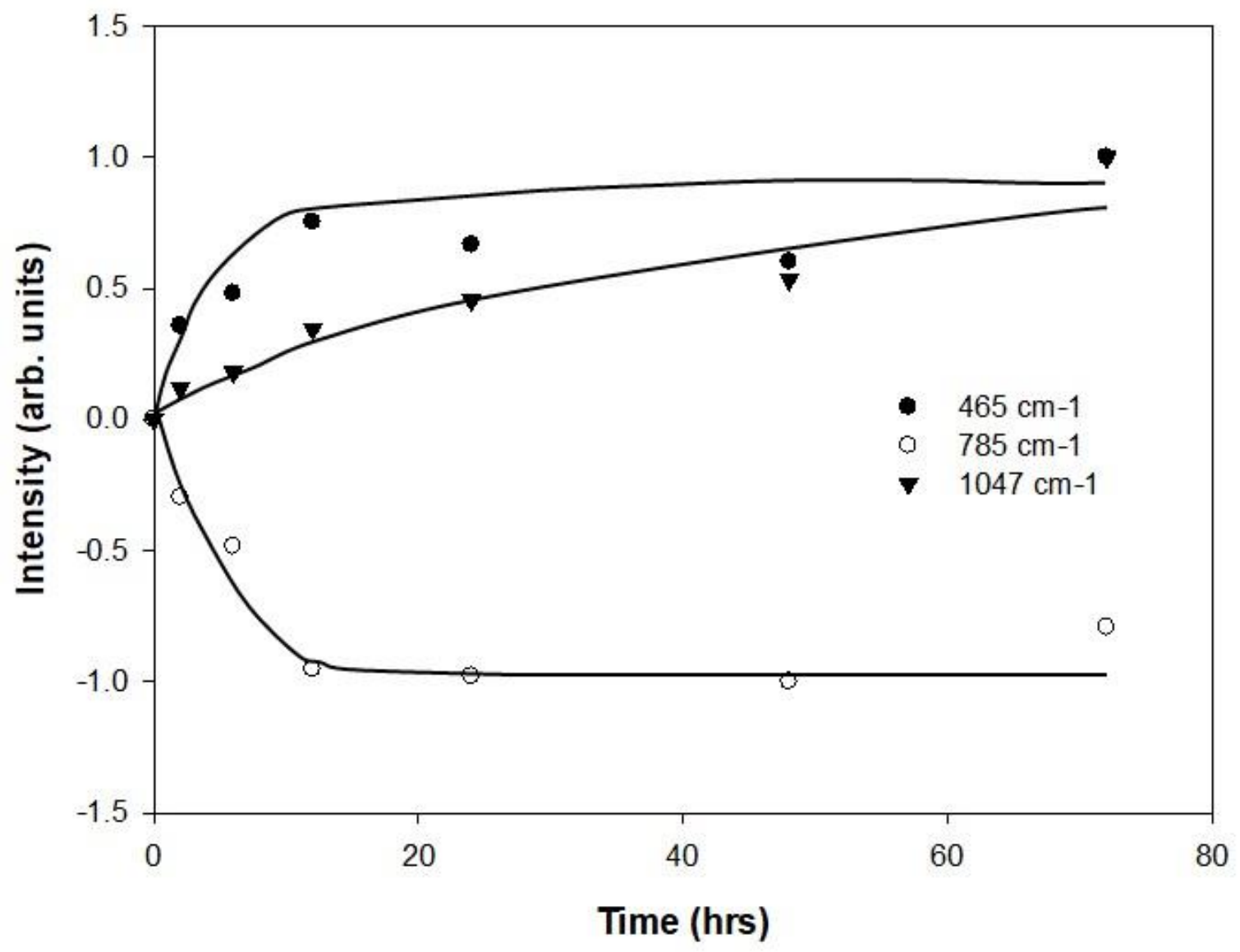

